\title{
Global mapping of 10-day differences of temperature and salinity in the intermediate layer observed with Argo floats
}

\author{
Yoshimi Kawai $^{1}$ D $\cdot$ Shigeki Hosoda ${ }^{1}$
}

Received: 30 March 2021 / Revised: 15 July 2021 / Accepted: 18 July 2021 / Published online: 3 August 2021

(c) The Author(s) 2021

\begin{abstract}
The authors examine small-scale spatiotemporal variability of the layer nearly 2000-m depth, which is the "bottom" of the present Argo observation system, using all of available Argo float data. The 10-day change, $\Delta T_{10}$, is defined as the difference of temperature between two successive observations with an interval of nearly 10 days for each individual float at an isobaric surface. $\left|\Delta T_{10}\right|$ is large along the western boundary currents at $1000 \mathrm{dbar}$, and becomes less remarkable with depth. At $1950 \mathrm{dbar}$, mean $\mid \Delta T_{10}$ is noticeable in the northeastern Atlantic Ocean (NEAO), the Argentine basin, and the northwestern Indian Ocean. In the Southern Ocean, large $\left|\Delta T_{10}\right|$ is localized in some areas located over the ridges or leeward of the plateau. Basically, $\Delta T_{10}$ at isobaric surfaces is accounted for by the heave component, but the spiciness component is dominant or comparable to the other in the NEAO and the Argentine basin. $\Delta T_{10}$ decreases with depth monotonically most of the world, suggesting that wind energy input is attenuated with depth. In some areas in the Southern Ocean, however, the vertical profile of $\left|\Delta T_{10}\right|$ implies enhanced bottom-induced turbulence. $\left|\Delta T_{10}\right|$ peaks at $1300 \mathrm{dbar}$ in the NEAO, corresponding to the spread of the Mediterranean Outflow Water. $\left|\Delta T_{10}\right|$ is smaller in the Pacific Ocean compared with the other oceans, but is enhanced along the equator, the Kuroshio and its Extension, the Kuril, Aleutian, Hawaii, and Mariana Islands, and the Emperor Seamount Chain.
\end{abstract}

Keywords Argo float $\cdot$ Intermediate layer $\cdot$ Heave $\cdot$ Spiciness $\cdot$ Short-term variation

\section{Introduction}

It has been indicated from repeat hydrographic observations to the bottom that the warming of the oceans already spread to the global abyssal waters (e.g.,Fukasawa et al. 2004; Kouketsu et al. 2011). Investigating processes of energy and material transport and their variations is essentially important for global climate changes. Argo is a global ocean observation network that consists of autonomous profiling floats (e.g., Wong et al. 2020). The floats have been deployed since the end of the 1990s, and have drastically increased temperature and salinity measurements to 2000-m depth in the twenty-first century. The observation frequency of every 10 days in a box of approximately $3 \times 3^{\circ}$ enabled us to examine spatiotemporal variations of temperature and salinity,

Yoshimi Kawai

ykawai@jamstec.go.jp

1 Japan Agency for Marine-Earth Science and Technology, Research Institute for Global Change, 2-15 Natsushima-Cho, Yokosuka 237-0061, Japan absolute geostrophic velocity, and vertical diffusivity around 1000-m depth or deeper, for example.

Using Argo data, Hosoda et al. (2006) detected westward propagation of temperature anomalies in the subtropical North Pacific Ocean at 1200 dbar, the phase speed of which was consistent with the theoretical speed of the first mode baroclinic Rossby wave. Mathews et al. (2007) found that the effect of the Madden-Julian Oscillation extended downward to 1500-m depth in the tropical western Pacific Ocean, and $\mathrm{Hu}$ and Wei (2013) also indicated the existence of intraseasonal oscillations at 1000-m depth in the regions, such as the Kuroshio, the Gulf Stream, and the Antarctic Circumpolar Current based on Argo observations. Hennon et al. (2014) analyzed hourly observations obtained from a set of 194 special Argo floats at a parking depth of $1000 \mathrm{~m}$, and successfully captured internal waves.

Numerical model studies have indicated that effects of atmospheric disturbances can propagate to the deep layer of the ocean. Kuwano-Yoshida et al. (2017) investigated explosive cyclones in the northwestern Pacific Ocean and their impact on the ocean by using an atmospheric reanalysis 
and an eddy-resolving ocean model. Although horizontal divergence caused by cyclones were confined to above $60-\mathrm{m}$ depth, storm-induced vertical velocity reached $5000 \mathrm{~m}$ depth. The deep-layer upwelling concentrated along the Hawaiian-Emperor seamount chain north of $40^{\circ} \mathrm{N}$, because blocking horizontal flow by the seamount reinforced the vertical motion. Another numerical study indicated that even horizontally homogeneous wind stress causes near-inertial motion field quickly becoming spatially heterogeneous in the existence of meso-scale horizontal gradient of surface relative vorticity, leading to the maximum of vertical velocity below the main thermocline around $1700 \mathrm{~m}$ depth (Danioux et al. 2008).

Researchers have insisted on the necessity of extending the ocean monitoring to $4000 \mathrm{~m}$ or deeper. The deep Argo floats that can measure the ocean below $2000 \mathrm{~m}$ have been deployed since 2012, and the number of the active deep Argo floats exceeded 130 in 2020. Kobayashi (2018) analyzed observations obtained with the deep Argo floats together with ship CTDs off the East Antarctica, and showed that the thickness of the Antarctic Bottom Water below $3000 \mathrm{~m}$ depth decreased since the 1990s and the reduction accelerated after 2011. The temporal trends of deep-layer temperatures are larger and detectable in the Atlantic and Southern Oceans (Kouketsu et al. 2011; Desbruyères et al. 2017). On the contrary, the shallow wind-driven circulation in the North Pacific Ocean is dominant for horizontal heat transport and the upper $700 \mathrm{~m}$ carries most of the meridional heat transport (e.g.,Bryden et al. 1991; Roemmich et al. 2001). Nevertheless, it is necessary to confirm the variability of the deep layer below $2000 \mathrm{~m}$ over the Pacific Ocean to effectively design the observation system of the deep Argo float.

In this study, we examine the variability of the layer around $2000 \mathrm{~m}$ depth, which is the "bottom" of the present, dense Argo observation system, using all available Argo float data since 1999. In particular, this study focuses on the difference between two successive observations, that is, 10-day change, aiming to detect rapid changes, such as effect of developed cyclones or internal tides. Even 1-day sampling, let alone 10-day sampling, is too coarse to resolve them, but a large number of samples will highlight areas where the frequency of large changes in a short period or on a small scale is high. We do not intend to directly capture the oscillations or upwelling. Analysis at $1000 \mathrm{dbar}$ is also shown for comparison. In Sect. 2, the data and method used in this study are explained. Section 3 shows the results for the globe. In Sect. 4, the vertical profiles of the 10-day change are shown, and we focus on some noticeable regions. Signals in the Pacific Ocean is smaller than in the other oceans, and we look closely at the Pacific Ocean in Sect. 5. Section 6 summarizes the conclusions.

\section{Data and method}

\subsection{Argo profile data}

The authors utilized temperature $(T)$, salinity $(S)$ and pressure data obtained by Argo profiling floats from the beginning of the Argo era to the present. These floats drift freely at a predetermined parking pressure (typically $1000 \mathrm{dbar}$ ), and conduct $T-S$ measurements between near the sea surface (approximately $5 \mathrm{dbar}$ ) and a depth of $2000 \mathrm{dbar}$. The profiling interval of most of the floats is set to 10 days, but some floats conducts the observations with an interval of less than 10 days. The collected data at about 70-120 sampling pressures, with a typical interval of $5 \mathrm{dbar}$ at depths shallower than $200 \mathrm{dbar}, 10-25 \mathrm{dbar}$ at 200-1000 dbar, and 50-100 dbar at deeper than $1000 \mathrm{dbar}$, are transmitted from the surfaced floats to satellites and are made freely available within $24 \mathrm{~h}$, after passing through the Argo real-time quality control (Argo 2021). We downloaded all of the delayed quality controlled float data that were available as of $20 \mathrm{Sep}-$ tember 2020 from the ftp site of Argo Global Data Assembly Center (available online at ftp://usgodae1.fnmoc.navy.mil/ pub/outgoing/argo; ftp://ftp.ifremer.fr/ifremer/argo) and analyzed only the measurements flagged as good. A total of approximately 10,000 floats were utilized for this study. The accuracies of the float data have been assessed using high-quality shipboard measurement, and concluded to be $0.002 \mathrm{~K}$ for temperature, $2.4 \mathrm{dbar}$ for pressure, and 0.01 PSS-78 for salinity (Wong et al. 2020).

Each profile was vertically interpolated on a 10-dbar grid using the Akima spline (Akima 1970). Then we obtained differences in properties between two successive observations for each individual float at an isobaric surface. The difference data with an observation interval of 9-12 days were selected and averaged on $2^{\circ} \times 2^{\circ}$ grid. They are referred to as "10-day variation", $\Delta T_{10}=T_{i}-T_{i-1}$ for temperature, and $\Delta S_{10}=S_{i}-S_{i-1}$ for salinity, where subscript $i$ denotes observation cycle. The advantage of our procedures is simplicity; you do not need to care drift of sensors or aliasing. We do not deal with spectrum analysis in this study. The Gibbs-SeaWater Oceanographic Toolbox was utilized to calculate spiciness and other parameters (McDougall and Barker 2011). Neutral density was computed using the PreTEOS-10 program released from http://www.teos-10.org/ preteos10_software/neutral_density.html.

\subsection{Gridded data set}

We also utilize a monthly gridded data set of temperature and salinity based on Argo float data (the Grid Point Value of the Monthly Objective Analysis: MOAA-GPV) (Hosoda et al. 2008). The used data for the MOAA-GPV are mainly 
obtained from Argo floats and vertically interpolated onto selected standard pressure levels from 10 to 2000 dbar using the Akima spline. The monthly data set of temperature and salinity consists of gridded values into $1^{\circ} \times 1^{\circ}$ fields using the two dimensional optimal interpolation method to be able to represent large scale variability with long-term change. As the spatial distribution of Argo profiles is not sufficient in 2003 or before (Toyama et al. 2015), we analyzed the data from 2004 to 2019 in this study. The de-trends standard deviations of temperature are calculated from the time series of anomaly from the monthly climatology (Sect. 3.3).

\section{Horizontal distribution}

\subsection{Global distribution}

First of all, the climatological mean fields of potential temperature and salinity are shown for 1000 and $1950 \mathrm{dbar}$

(a) $1000 \mathrm{dbar} /$ Potential temperature

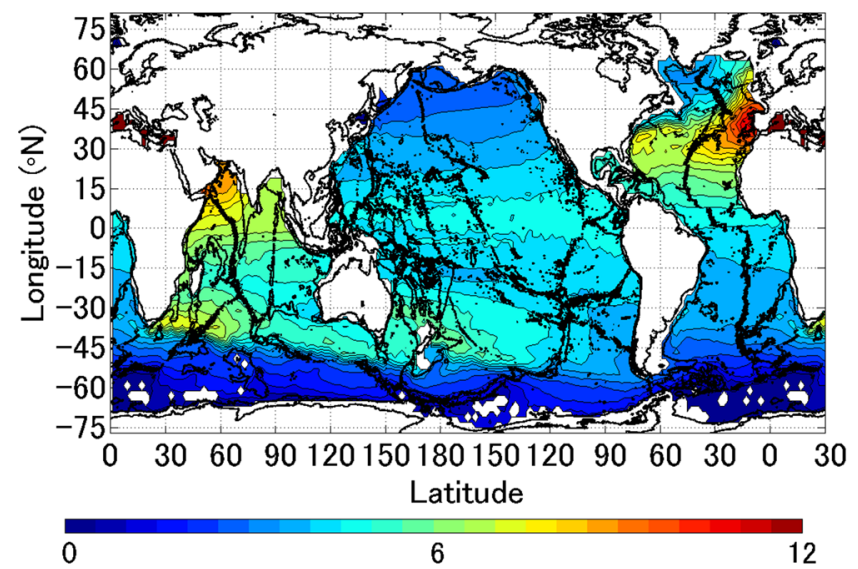

(c) $1000 \mathrm{dbar} /$ Salinity

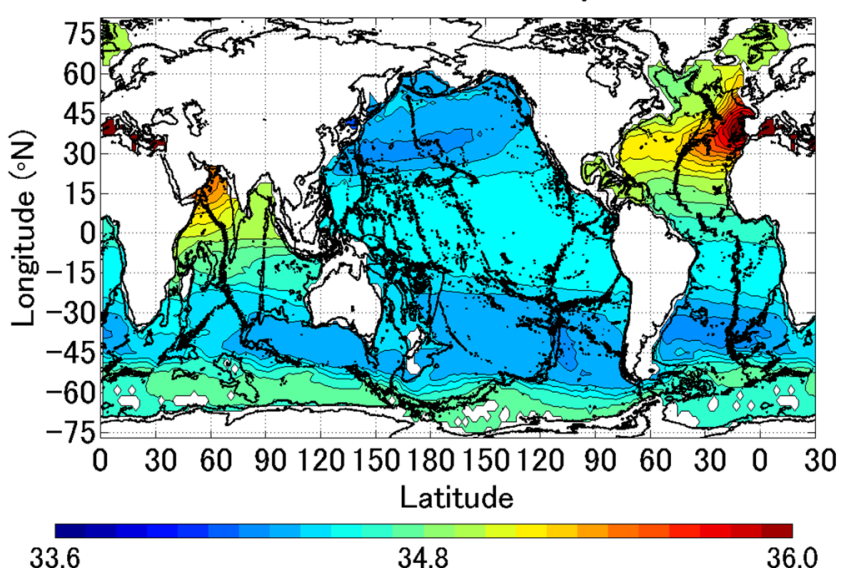

Fig. 1 Climatological mean of $\mathbf{a}, \mathbf{b}$ potential temperature, and $\mathbf{c}, \mathbf{d}$ salinity. Left panels a, c for 1000 dbar, and right panels $\mathbf{b}, \mathbf{d}$ for 1950 dbar. They were calculated from all profile data throughout the Argo
(Fig. 1). Warm, saline water is distributed in the northeastern Atlantic Ocean (NEAO) west of Europe. This is the Mediterranean Outflow Water (MOW), which is a saline and warm water mass produced as a result of mixing the Mediterranean Sea Water and the ambient North Atlantic Central Water. This water mass occupies the intermediate depths of the NEAO (Bozec et al. 2011). Another warm, saline region can be seen in the northwestern Indian Ocean (NWIO), where the Red Sea overflow water spreads. Temperature and salinity of the Pacific Ocean are lower compared with the Atlantic and Indian Oceans, and their horizontal gradients are also small in the Pacific Ocean. Relatively warm, fresh water extends from the southern tip of Africa to east of New Zealand, forming a band of low density, and large density gradient is located along the Circumpolar Current.

Mean $\left|\Delta T_{10}\right|$ at 1000 dbar exceeds $0.2 \mathrm{~K} / 10$ days in the WBCs: the Gulf Stream, the North Atlantic Current, the Agulhas and Agulhas Return Currents, the East Australian Current, the Brazil Current, and the Kuroshio

(b) $1950 \mathrm{dbar} /$ Potential temperature

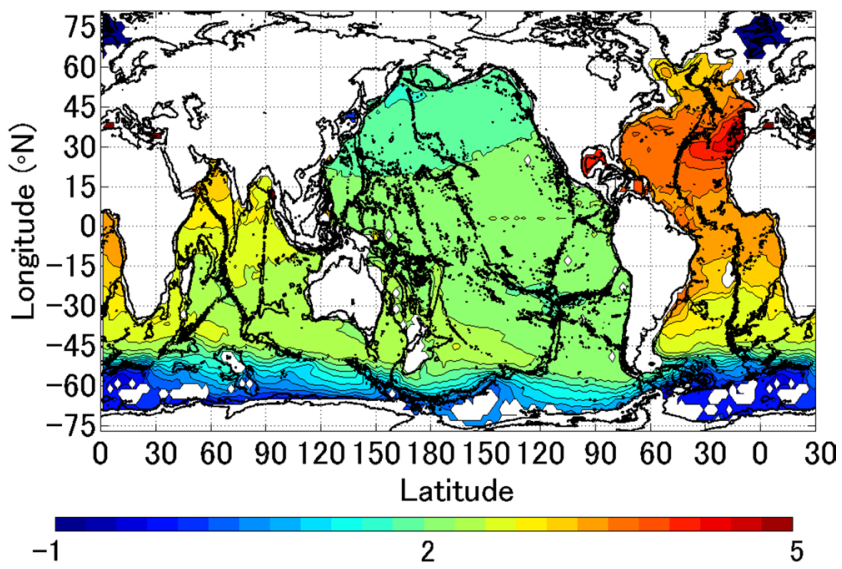

(d) $1950 \mathrm{dbar} /$ Salinity

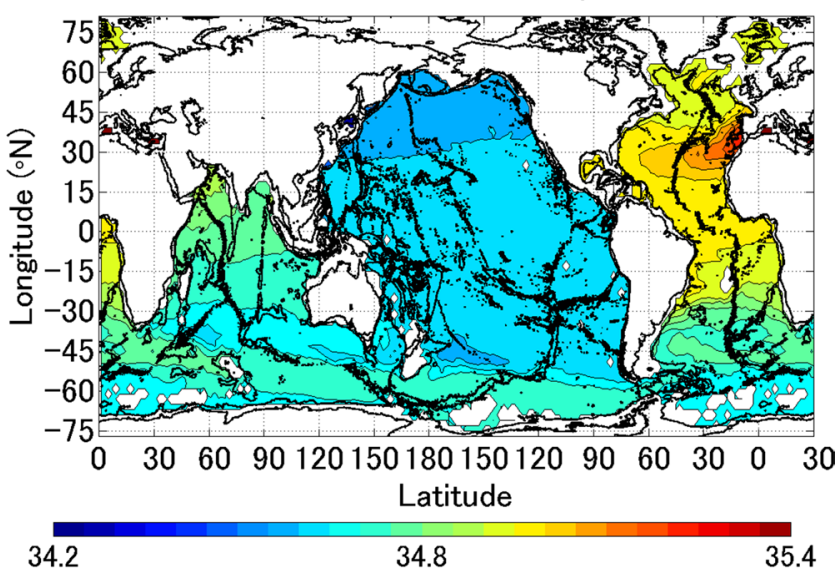

era without optimum interpolation. Black lines show the contours of 0 and $3000 \mathrm{~m}$ depth (color figure online) 
Extension (Fig. 2a). At $1950 \mathrm{dbar}$, mean $\left|\Delta T_{10}\right|$ is more than $0.1 \mathrm{~K} / 10$ days in the NEAO, the Argentine basin, and the NWIO (Fig. 2b). Large $\left|\Delta T_{10}\right|$ is localized in some areas in the Southern Ocean: around $30^{\circ} \mathrm{E}, 85^{\circ} \mathrm{E}, 155^{\circ} \mathrm{E}, 135^{\circ} \mathrm{W}$, and the Scotia Sea (Fig. 3). On the contrary, $\left|\Delta T_{10}\right|$ becomes less noticeable in the WBCs at $1950 \mathrm{dbar}$, except for the South Atlantic Ocean. $\Delta T_{10}$ is enhanced along the equator, too. For salinity, the spatial patterns are basically similar to those of (a) $1000 \mathrm{dbar} / \mathrm{Tdif}$ mean

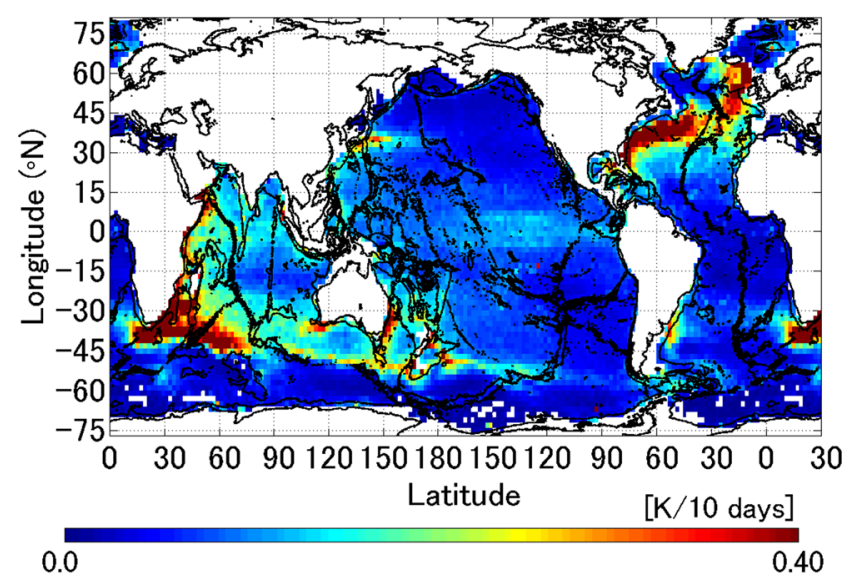

(c) $1000 \mathrm{dbar} /$ Sdif mean

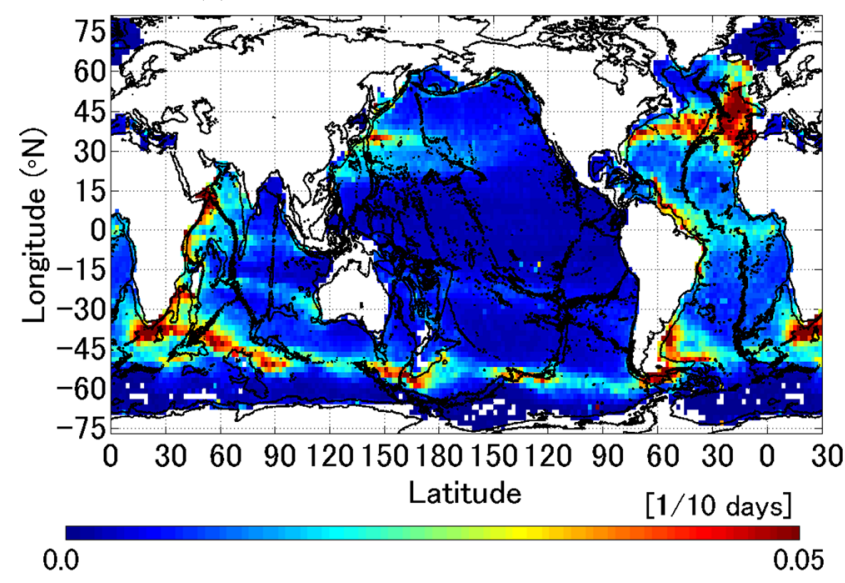

(e) $1000 \mathrm{dbar} /$ Number of sample

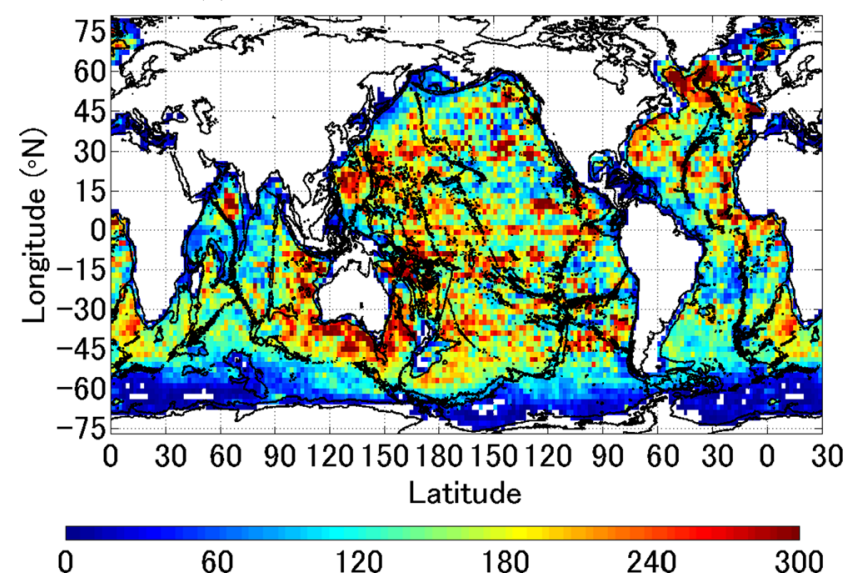

(b) $1950 \mathrm{dbar} /$ Tdif mean

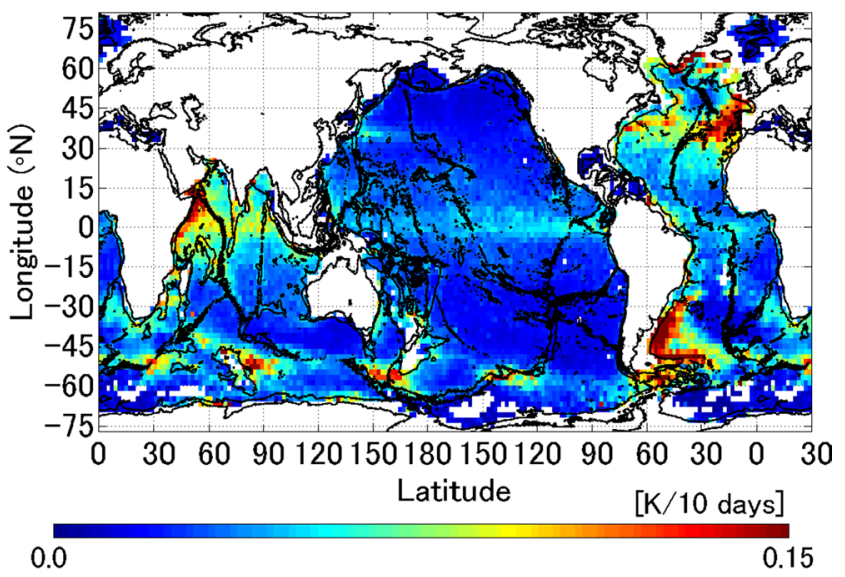

Fig. 2 Mean of $\mathbf{a}, \mathbf{b}\left|\Delta T_{10}\right|$ and $\mathbf{c}, \mathbf{d}\left|\Delta S_{10}\right|$, and $\mathbf{e}, \mathbf{f}$ the number of the difference in a $2^{\circ} \times 2^{\circ}$ grid throughout the period. Left panels a, $\mathbf{c}, \mathbf{e}$ for $1000 \mathrm{dbar}$, and right panels $\mathbf{b}, \mathbf{d}, \mathbf{f}$ for $1950 \mathrm{dbar}$

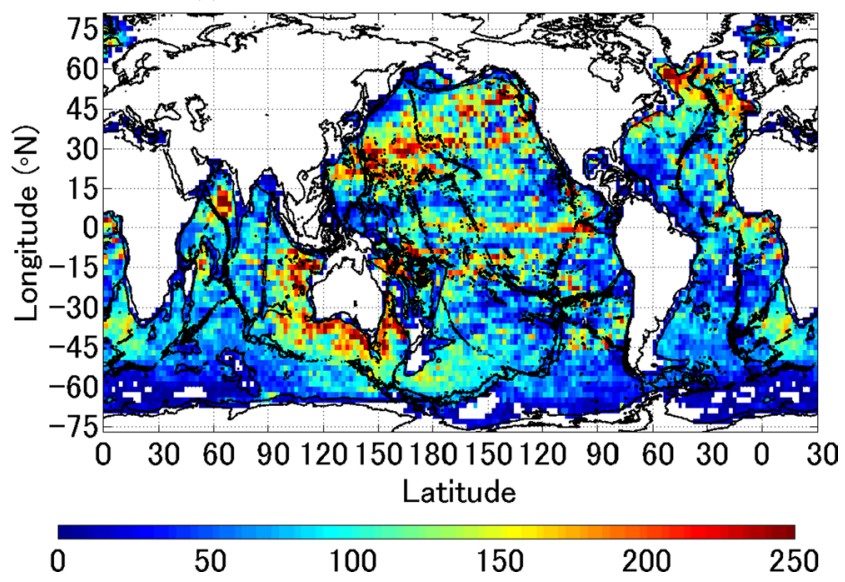




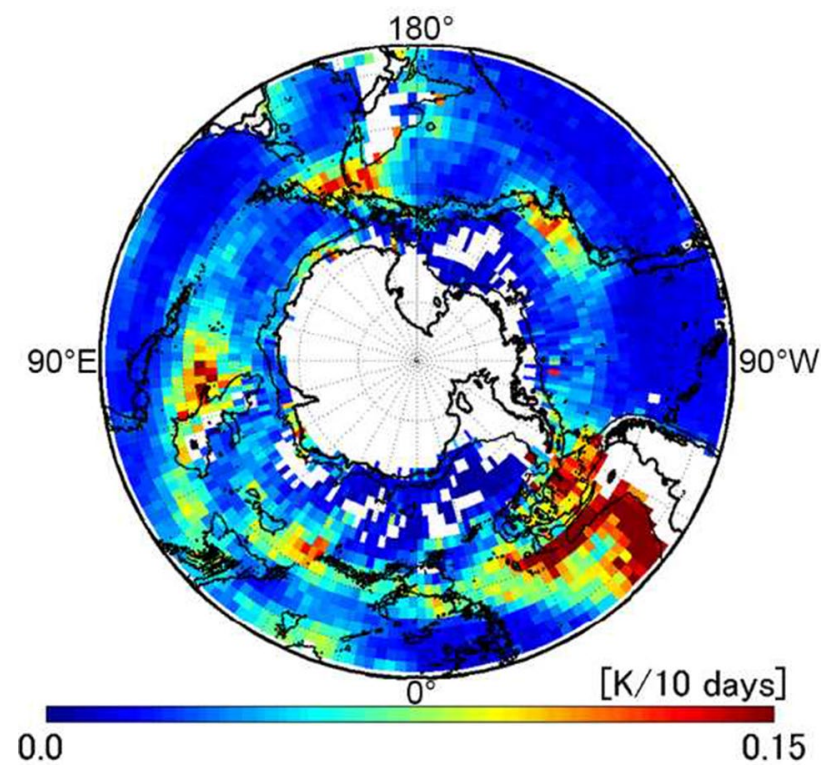

Fig. 3 Mean of $\left|\Delta T_{10}\right|$ at 1950 dbar in the Southern Ocean south of $35^{\circ} \mathrm{S}$. The data shown here are the same as Fig. $2 \mathrm{~b}$

temperature, but $\mid \Delta S_{10} \mathrm{l}$ is also large at 1000 dbar west of Europe (Fig. 2c, d). The Argo floats are distributed all over the world except the Arctic Ocean. The number of samples is relatively small in the Indian and Southern Oceans (Fig. 2e, f). There is no clear seasonality in the 10-day variations at $1000 \mathrm{dbar}$ or deeper (not shown).

The large $\left|\Delta T_{10}\right|$ and $\left|S_{10}\right|$ at $1000 \mathrm{dbar}$ are collocated with the regions of strong mean flow and high eddy kinetic energy (Fig. 3a of Roach et al. 2018). Basically the 10-day variation would reflect turbulence induced by strong currents, and $T / S$ horizontal fronts. The notable difference in $\left|\Delta T_{10}\right|$ between the Gulf Stream and Kuroshio Extension regions, however, cannot be accounted for by these factors. At $1000 \mathrm{dbar}$, the Brunt-Vaisala frequency is larger in the Gulf Stream and Agulhas Current regions than in the Kuroshio Extension and Brazil Current regions (Fig. 4a); internal waves with higher frequency can exist in the former regions, and greater vertical gradient of $T$ enhances $\left|\Delta T_{10}\right|$ due to the heave motion (see Sect. 3.4). Furthermore, the Turner angle exceeds $45^{\circ}$ in the North Atlantic and Indian Oceans (Fig. 4c), which means that a water column is unstable to salt fingering. On the contrary, it is statically stable in the Pacific and South Atlantic Oceans. These factors affect small-scale spatiotemporal variability, and would yield the differences at 1000 dbar between the Oceans. At 1950 dbar, the spatial pattern of the vertical gradient of potential density, proportional to the Brunt-Vaisala frequency squared (Fig. 4b), does not correspond to that of the mean $\left|\Delta T_{10}\right|$ (Fig. 2b). The large $\left|\Delta T_{10}\right|$ in the NEAO and NWIO may be related with the instability of the salt-finger type, and diffusive convection would partly contribute to enhancing the variability in the South Atlantic (Fig. 4d).

\subsection{Effect of horizontal shift}

$\Delta T_{10}$ or $\Delta S_{10}$ is composed of both temporal and spatial changes, since floats move horizontally in 10 days. The effect of the horizontal shift is estimated as $\Delta \boldsymbol{x}_{10} \cdot \nabla T$, where $\Delta \boldsymbol{x}_{10}$ is a vector of position difference between two successive observations, and $T$ is temperature at an isobaric surface, and the monthly MOAA-GPV data are used to evaluate the temperature gradient.. The averages of $\left|\Delta x_{10} \cdot \nabla T\right|$ and $\left|\Delta T_{10}-\Delta x_{10} \cdot \nabla T\right|$ are shown in Fig. 5 . At 1000 and 1950 dbar, the temperature difference due to horizontal shift is large, where current speed is high, and especially noticeable and comparable to $\Delta T_{10}$ in the Southern Ocean (Fig. 5a, b). Nevertheless, the mean corrected $\left|\Delta T_{10} \mathrm{l},\right| \Delta T_{10}-\Delta \boldsymbol{x}_{10} \cdot \nabla T \mid$, (Fig. 5c, d) is almost identical to the uncorrected (Fig. 2a, b). For salinity, the results are almost the same as temperature (not shown)., Based on this estimation, we infer that the contribution of horizontal shift to $\Delta T_{10}$ is relatively small, except for in the vicinity of $T$ or $S$ fronts, and $\Delta T_{10}$ is mainly accounted for by temporal change. It should be noted that small-scale variations would be smoothed out due to optimum interpolation in the MOAA-GPV data, and the horizontal gradient might be larger in the real ocean.

\subsection{Comparison with the standard deviation of the MOAA-GPV data}

We also checked the variability of the monthly gridded data set (Fig. 6). Linear trends were removed when calculating standard deviations to focus on relatively short term variations. The spatial distributions of the mean $\left|\Delta T_{10}\right|$ at 1000 and 1950 dbar (Fig. 2a, b) are similar to the monthly standard deviations, but the former has clearer, finer horizontal structure. In addition, clear differences can be seen in the Pacific and Atlantic equatorial regions, and around the Kuril and Aleutian Islands (see also Fig. 11a, b); temperature variation is relatively small in the MOAA GPV data. One of the reasons will be spatial smoothing in the gridded data set, and fluctuations with a time scale of less than 1 month might be smoothed out. In other words, our mean $\left|\Delta T_{10}\right|$ successfully captures small-scale spatiotemporal variations that does not appear in the monthly data.

\subsection{Spiciness and heave}

The change of temperature or salinity at a given depth is the sum of the effects of vertical displacement (heave) and temperature/salinity changes along isopycnal surfaces (spiciness): 
(a) $1000 \mathrm{dbar}$

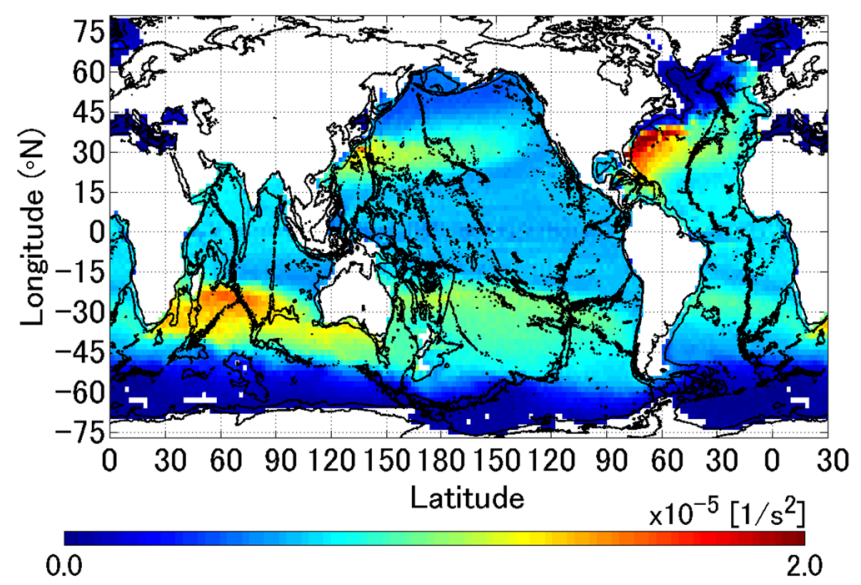

(c) $1000 \mathrm{dbar}$

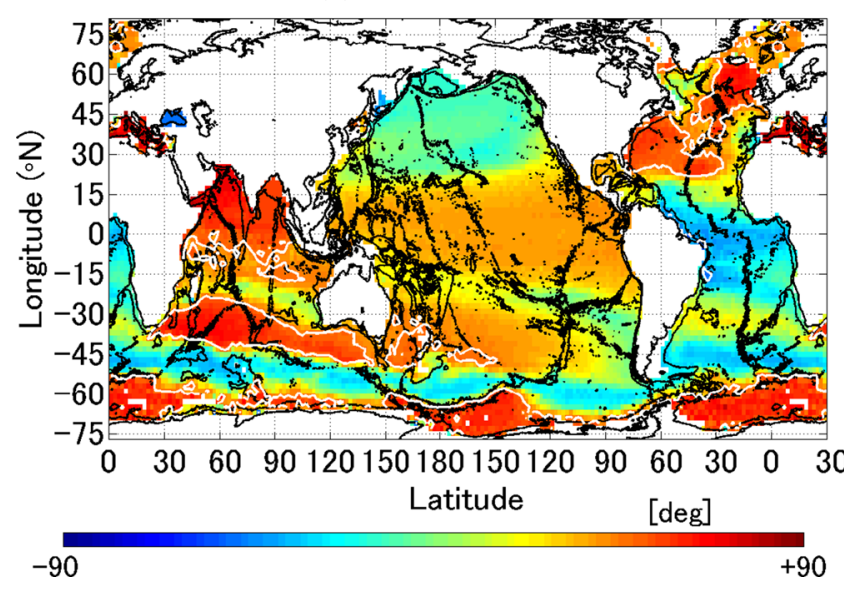

(b) $1950 \mathrm{dbar}$

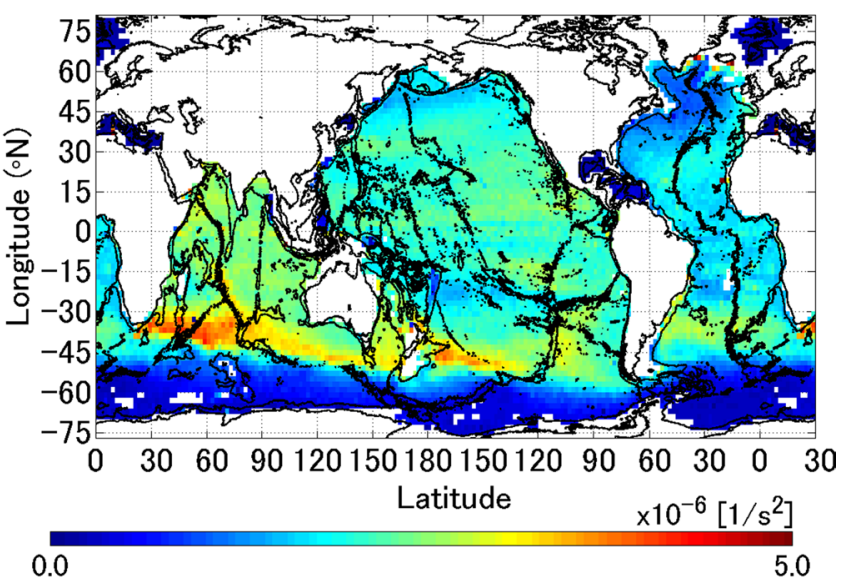

(d) $1950 \mathrm{dbar}$

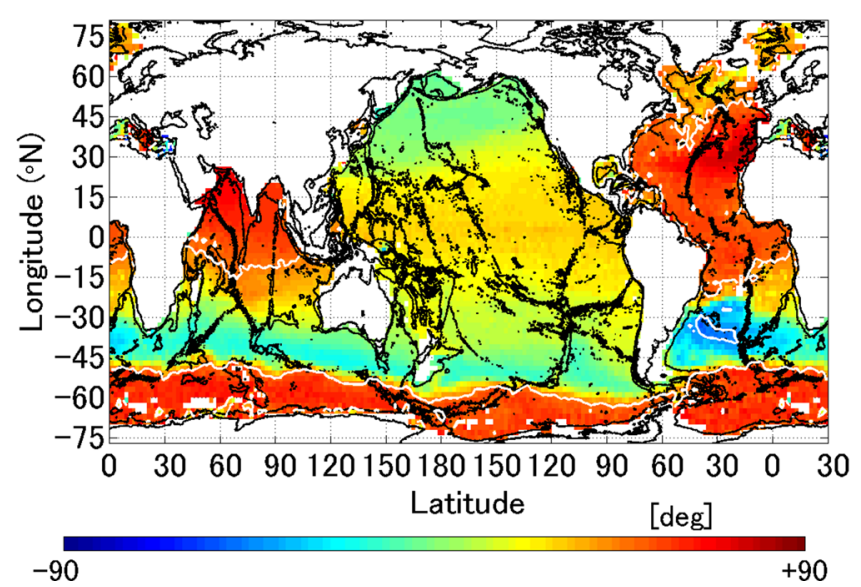

Fig. 4 a, b Brunt-Vaisala frequency squared and c, d Turner angle. Left panels a, c for 1000 dbar, and right panels b, d for 1950 dbar. White contours in $\mathbf{c}, \mathbf{d}$ denote an angle of $\pm 45^{\circ}$ (color figure online)

$\left.\left.\Delta T_{10} \approx \frac{\mathrm{d} T}{\mathrm{~d} t}\right|_{\mathrm{p}} \approx \frac{\mathrm{d} T}{\mathrm{~d} t}\right|_{\mathrm{n}}-\left.\frac{\mathrm{d} p}{\mathrm{~d} t}\right|_{\mathrm{n}}\left(\frac{\mathrm{d} T}{\mathrm{~d} p}\right)$,

where subscript $\mathrm{p}$ and $\mathrm{n}$ represents differential along pressure surfaces and neutral density surfaces, respectively (Desbruyères et al. 2017). The total 10-day changes at isobaric surfaces (Fig. 2a, b) are mainly accounted for by the heave component (Fig. 7c, d). Spiciness changes are relatively large in the Indian Ocean east of Africa and NEAO at 1000 dbar (Fig. 7a). At 1950 dbar, the variations of spiciness are noticeable in the Argentine basin and the NEAO, where the spiciness component is dominant or comparable to the other (Fig. 7b).

\section{Vertical structure}

The vertical distribution of $\left|\Delta T_{10}\right|$ below $700 \mathrm{dbar}$, in which the mixed layer is rarely included, is examined for some intriguing regions. Basically, $\left|\Delta T_{10}\right|$ is dominated by the heave component, and decreases with depth monotonically most of the world (Fig. 8b), which implies that the source of the variation is not at the bottom but at the surface. The same applies to the NWIO, but the decreasing rate with respect to depth is relatively small and the effect of the spiciness change is stronger compared with the global mean (Fig. 8c). The saline outflow from the Red Sea and/or the monsoon might be associated with them. The Red Sea water (RSW) spreads mainly southward in the intermediate layer along the African coast through the Mozambique Channel into the Agulhas Current (Beal et al. 2000). The intermediate salinity maximum of the RSW disappears south of the Channel due 
(a) $1000 \mathrm{dbar} / \mathrm{Tdif}$

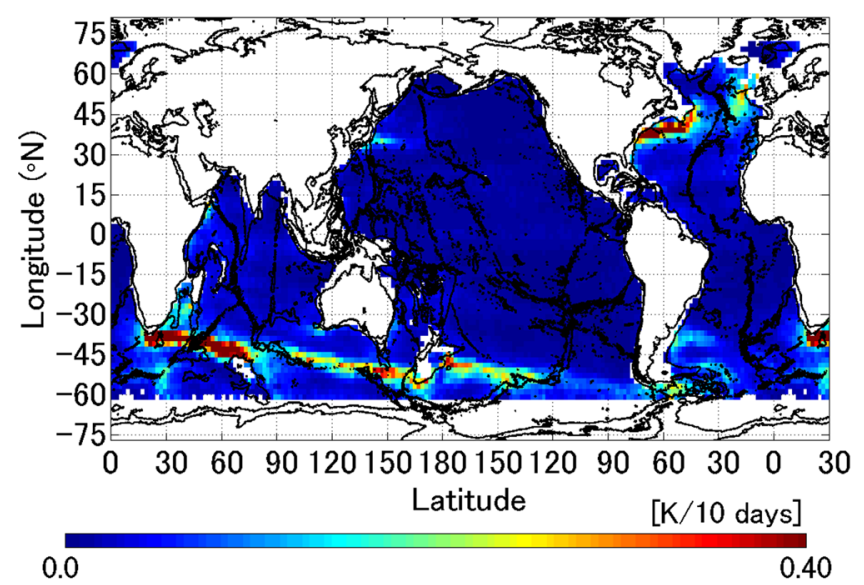

(c)

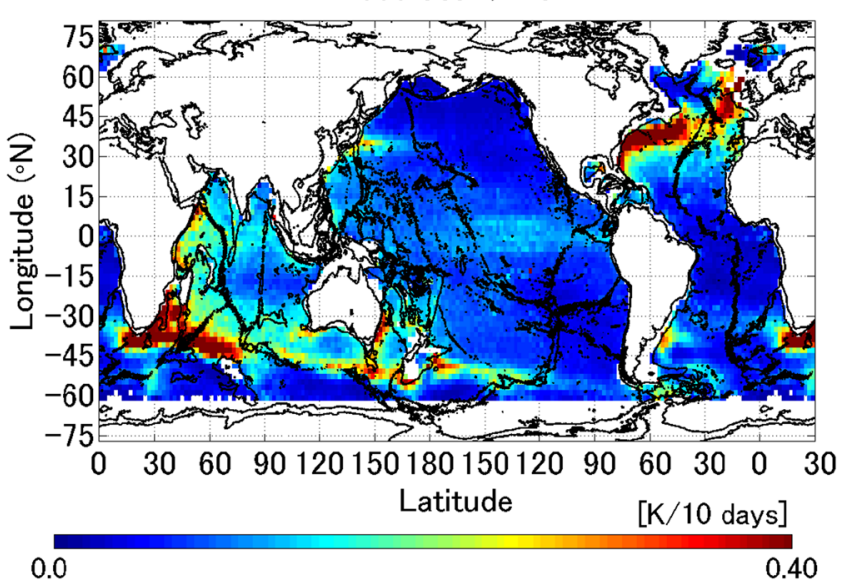

(b) $1950 \mathrm{dbar} /$ Tdif

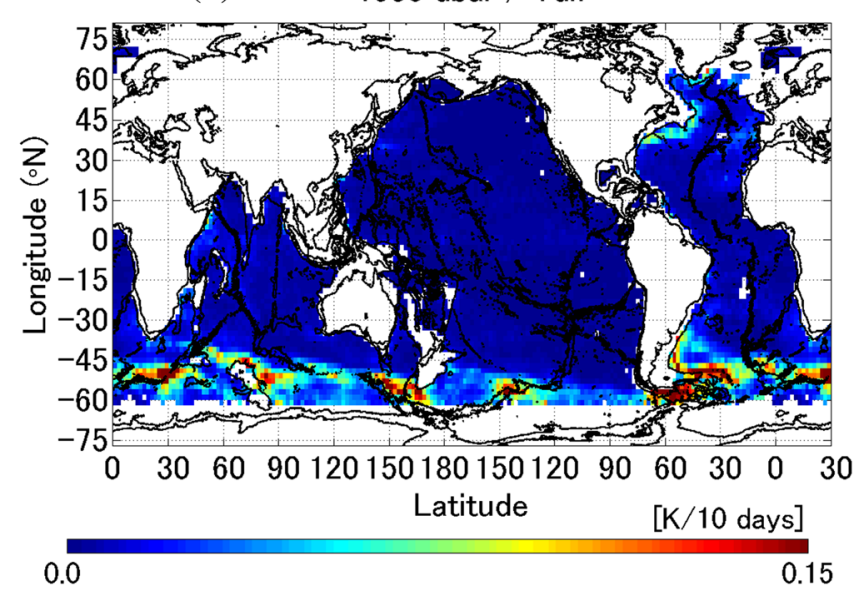

(d)

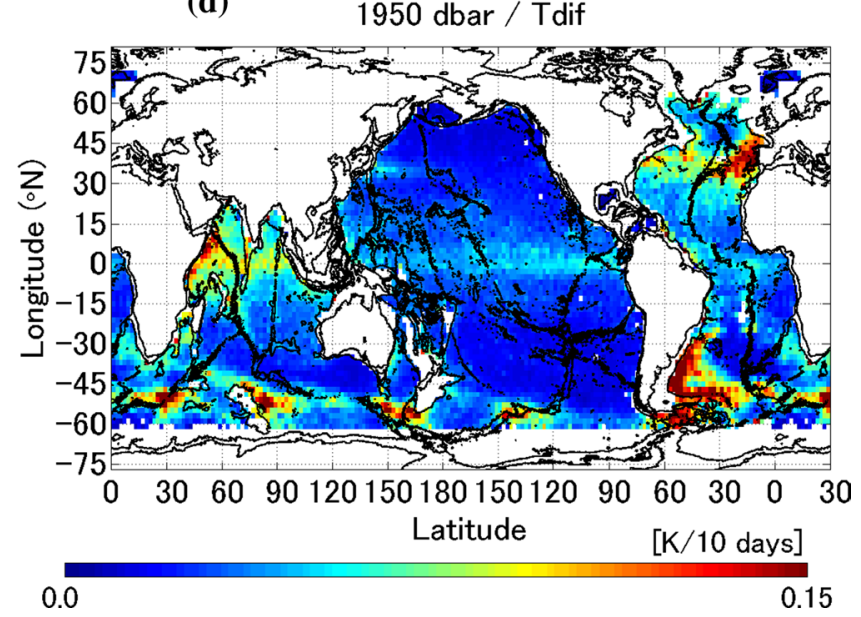

Fig. 5 Mean of $\mathbf{a}, \mathbf{b}$ the component of horizontal displacement, $\left|\Delta \boldsymbol{x}_{10} \cdot \nabla \bar{T}\right|$, and $\mathbf{c}, \mathbf{d}$ corrected $\left|\Delta T_{10}\right|,\left|\Delta T_{10}-\Delta \boldsymbol{x}_{10} \cdot \nabla \bar{T}\right|$. Left panels $\mathbf{a}, \mathbf{c}$ for $1000 \mathrm{dbar}$, and right panels $\mathbf{b}, \mathbf{d}$ for $1950 \mathrm{dbar}$

to mixing with the fresh Antarctic Intermediate Water. The advection and isopycal mixing of the RSW may correspond to the relatively large spiciness changes along the African coast (Figs. $7 \mathrm{a}, \mathrm{b}$ and $8 \mathrm{c}$ ).

For the area of $54-60^{\circ} \mathrm{S}, 120-150^{\circ} \mathrm{W}$ in the Southern Ocean, $\left|\Delta T_{10}\right|$ is nearly homogeneous below 1200 dbar, where the spiciness component is small (Fig. 8d). This suggests that the effect of bottom-induced turbulence spread to around $1200 \mathrm{~m}$ depth. (The reason why there is no obvious maximum below 1200 dbar would be that the turbulence from the bottom is not so strong enough to make a maximum above $2000 \mathrm{dbar}$.) The differences in $\left|\Delta T_{10}\right|$ between 1950 and $1300 \mathrm{dbar}$ are nearly zero or slightly positive around the Antarctic circumpolar current (Fig. 9), including the areas east of the Kerguelen Plateau around $55^{\circ} \mathrm{S}, 80^{\circ} \mathrm{E}$, southwest of the Campbell Plateau around $55^{\circ} \mathrm{S}, 160^{\circ} \mathrm{E}$, southwest of the Prince Edward Islands around $50^{\circ} \mathrm{S}, 30^{\circ} \mathrm{E}$, and the Scotia
Sea, where $\left|\Delta T_{10}\right|$ is locally enhanced at 1950 dbar (Figs. $2 \mathrm{~b}$ and 3). These areas are located over the ridges or leeward of the plateau. Nikurashin and Ferrari (2011) estimated energy conversion rate to internal lee waves from geostrophic flows from linear theory (their Fig. 2). The large $\left|\Delta T_{10}\right|$ areas in the Southern Ocean are included in the region of high energy conversion rate, and might be related with internal lee waves.

On the other hand, $\left|\Delta T_{10}\right|$ is maximized at $1300 \mathrm{dbar}$ in the NEAO (Fig. 8e). In this area, both the heave and spiciness components contribute to large $\mid \Delta T_{10} \mathrm{l}$. The depth of the maximum $\left|\Delta T_{10}\right|$ is consistent with the layer where the MOW spreads, which would contribute to enhancing $\left|\Delta T_{10}\right|$. Ferrari and Polzin (2005) showed large isopycnal $T-S$ variability at the level of the Mediterranean Water (about 900-1400 dbar) around $26^{\circ} \mathrm{N}, 29^{\circ} \mathrm{W}$, where is somewhat south off the area of Fig. 6e, using high-resolution profiler (their Fig. 3). They indicated that the density-compensated variability was 
(a) Detrended standard deviation: 1000

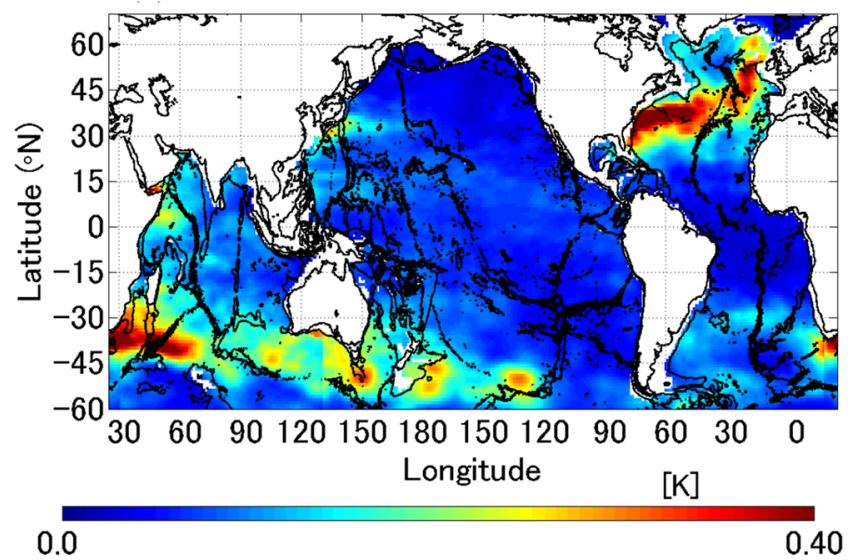

(c) Detrended standard deviation: 1000

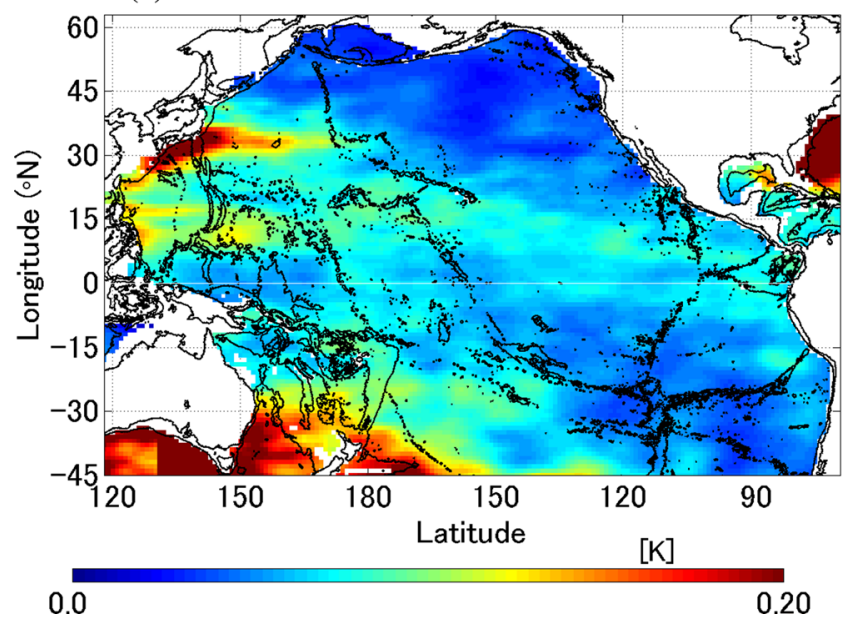

Fig. 6 a, b Detrended standard deviation of monthly temperature anomalies in 2004-2019. Panels c, $\mathbf{d}$ shows an enlargement of part a, b focusing the Pacific Ocean. Note that the color scales are different

generated by mesoscale eddy stirring: large-scale isopycnal $T-S$ gradient caused by the MOW resulted in a rich fine scale structure through filamentogenesis. The heave components also show the maximum around 1300 dbar in our analysis, suggesting vigorous diapycnal mixing that changes density.

Temperature fluctuation shows a peculiar vertical profile in the Argentine basin: it becomes minimum at around 1300 dbar and increases with depth below 1500 dbar, and large $\mid \Delta T_{10} \mathrm{l}$ in the deeper layer is due to the spiciness change (Figs. 8f and 9). The variation of spiciness suggests vigorous horizontal shift or mixing of water masses around 2000 dbar or deeper. At this depth in this region, the Deep Western Boundary Current (DWBC) conveys the North Atlantic Deep Water (NADW) with higher $T$ and $S$ along the coast southward to around $40^{\circ} \mathrm{S}$ (Fig. 10). Meanwhile, the cold, fresh Circumpolar Deep Water enters the Argentine basin (b) Detrended standard deviation: 2000

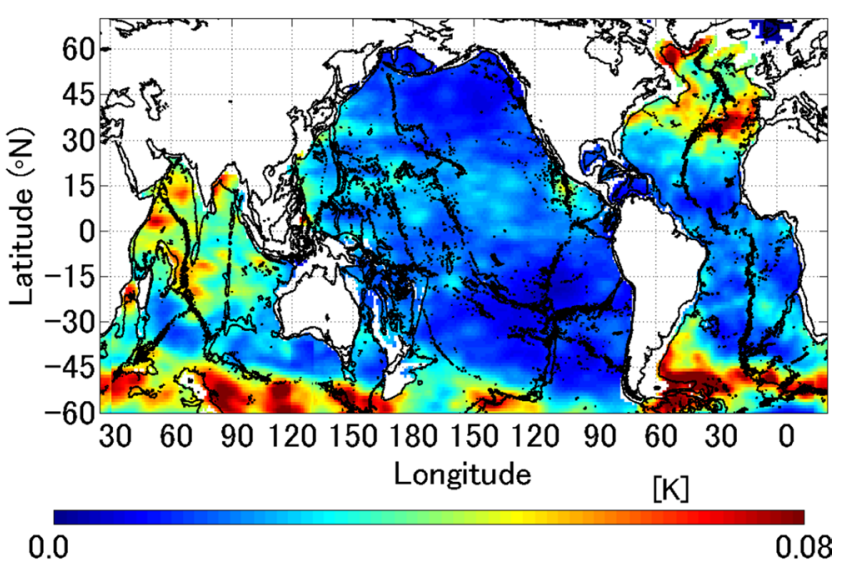

(d) Detrended standard deviation: 2000

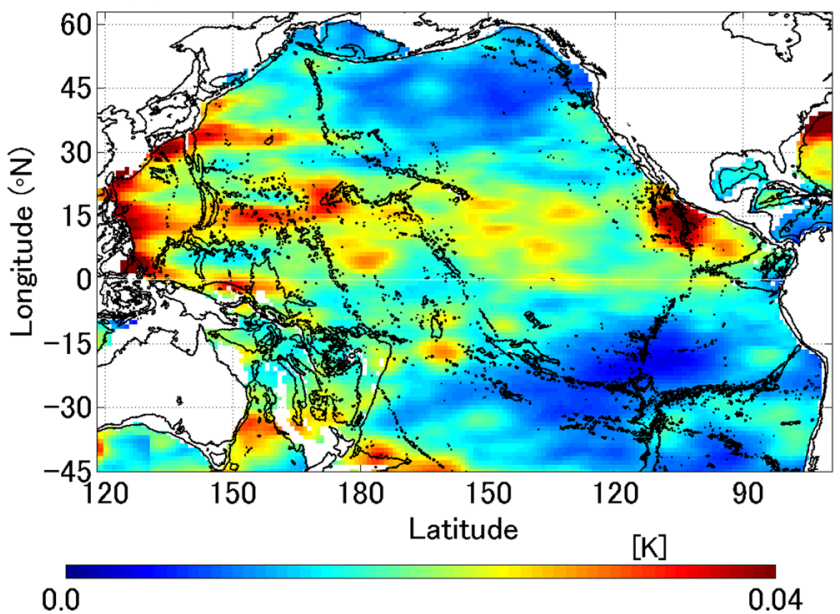

between the panels. Left panels a, $\mathbf{c}$ for $1000 \mathrm{dbar}$, and right panels $\mathbf{b}$, d for 2000 dbar. The anomalies were derived from the MOAA GPV data set (color figure online)

along the coast northward. These two water masses form large horizontal $T / S$ gradients. A zonal band of warm, fresh water can be seen around $35-40^{\circ} \mathrm{S}$. The densities of NADW and the upper CDW are close to each other (Fig. 10c), and isopycnal mixing of these water masses is apt to occur. Valla et al. (2018) showed standard deviation sections of potential temperature, $S$, and dissolved oxygen concentration along $34.5^{\circ} \mathrm{S}$ using ship and Argo data, and there were their maxima around $2000 \mathrm{dbar}$, minima around $1400 \mathrm{dbar}$ east of $50^{\circ} \mathrm{W}$ (their Fig. 3e-g and Table 3), which is consistent with our result. They suggested that the intensified variability was due to an energetically meandering DWBC that generated occasional excursions of NADW away from the continental shelf.

Weak inversion structure, slightly larger $\left|\Delta T_{10}\right|$ at 1950 dbar than at $1300 \mathrm{dbar}$, can be seen in the tropical Atlantic 
(a) $1000 \mathrm{dbar}$, spiciness

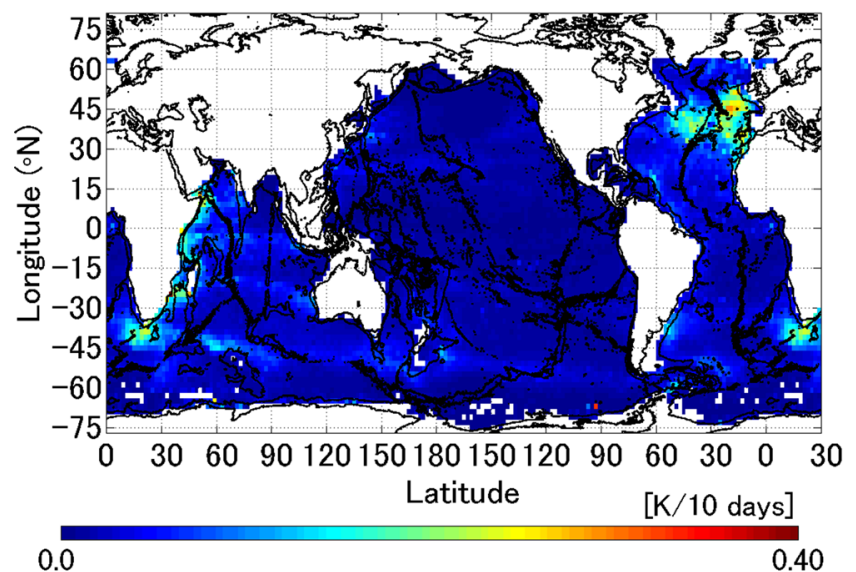

(b) 1950 dbar, spiciness

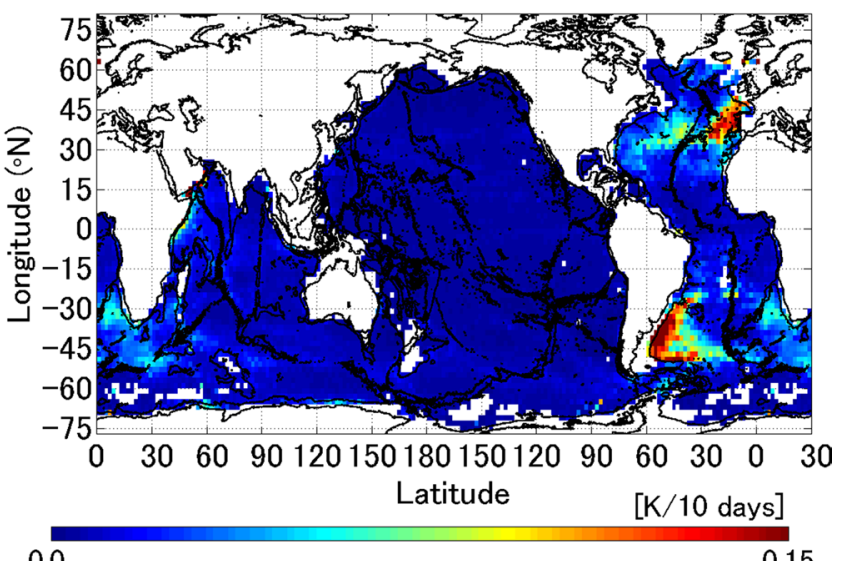

(d) 1950 dbar, heave

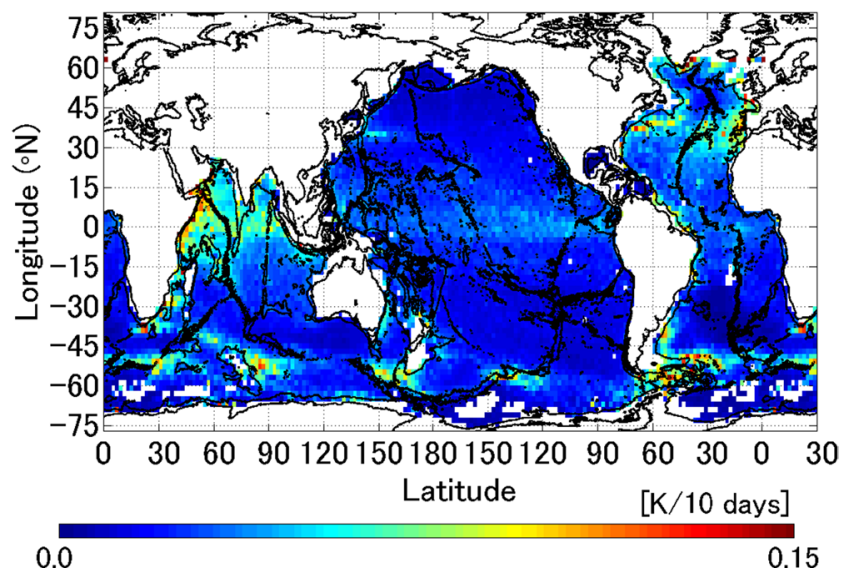

Fig. 7 Mean of the component of $\mathbf{a}, \mathbf{b}$ spiciness, and $\mathbf{c}, \mathbf{d}$ heave. Left panels $\mathbf{a}, \mathbf{c}$ for $1000 \mathrm{dbar}$, and right panels $\mathbf{b}, \mathbf{d}$ for $1950 \mathrm{dbar}$

Ocean and the Labrador Sea (Fig. 9), where the heave component slightly increases with depth (not shown). The saltfinger instability might contribute to forming these profiles (Fig. 4d). Danioux et al. (2008) theoretically indicated the deep maximum of vertical velocity around $1700 \mathrm{dbar}$ due to wind-forced near-inertial motions. We attempted to extract principal vertical modes over the globe, but could not find a clear, convincing mode that has a maximum around 1700 dbar (not shown). This mode might have too small horizontal scales to be captured by the present standard Argo sampling.

\section{Pacific Ocean}

The intermediate and deep layers in the Pacific Ocean are quiescent compared with the Atlantic and Southern Oceans. $\Delta T_{10}$ and $\Delta S_{10}$ are expected to reflect turbulent mixing, which provides deep waters with buoyancy, and the lack of deep overturn would be related with less variability of $T / S$. Turbulent mixing that results from internal waves, which cause vertical displacement of isopycnal surfaces, contribute to the heave component rather than the spiciness component. The small I $\Delta T_{10} \mid$ and $\left|\Delta S_{10}\right|$ shown in Fig. 2 prove that the Pacific Ocean is certainly calm. We here focus on the Pacific fluctuations. At both 1000 and 1950 dbar, mean $\left|\Delta T_{10}\right|$ is especially large in regions of strong currents: along the East Australian Current, the Kuroshio and Kuroshio Extension, and in the eastern tropics (Fig. 11a, b). The fluctuation is 
(a)

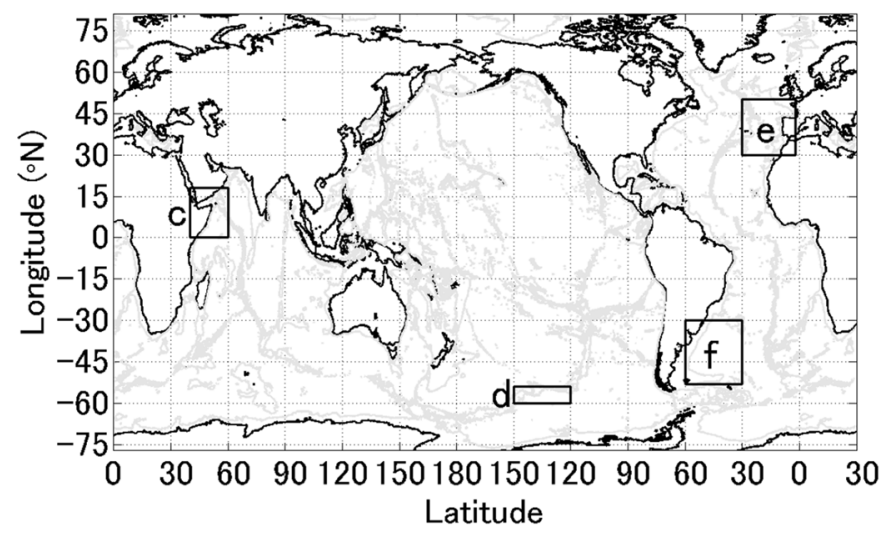

(c) $\quad 0-18{ }^{\circ} \mathrm{N}, 40-60^{\circ} \mathrm{E}$

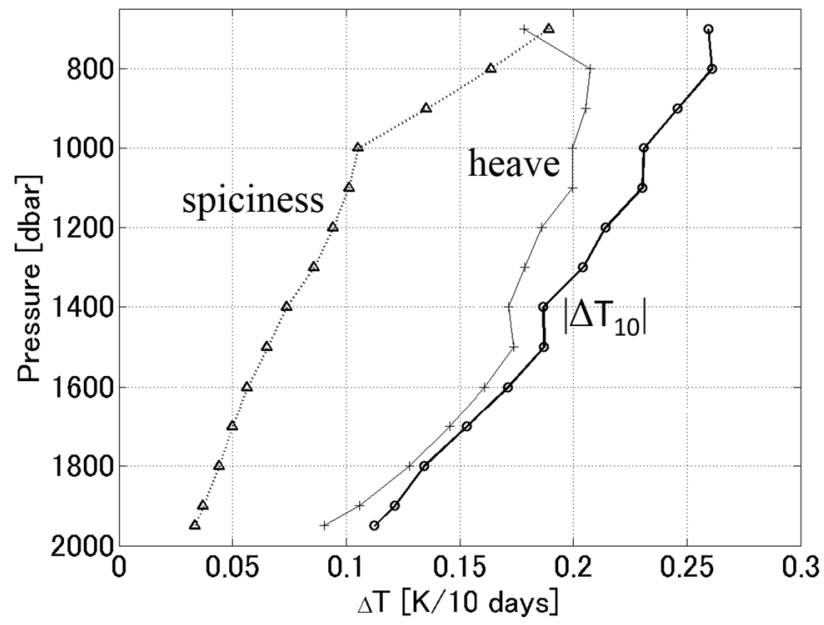

(e) $\quad 30-50 \circ \mathrm{N}, 2-30 \circ \mathrm{W}$

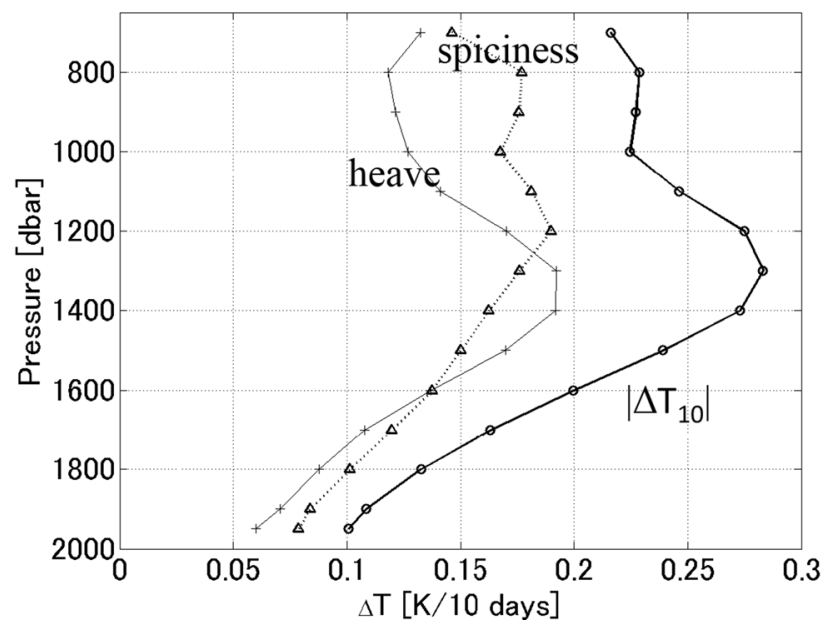

Fig. 8 Vertical profiles of mean $\left|\Delta T_{10}\right|$ (bold line with circles). The location of the selected regions are shown in panel (a). Thin solid line with pluses and broken line with triangles in panels (b-f) show the heave and spiciness component, respectively. b Globe, $\mathbf{c} 0-18^{\circ} \mathrm{N}$, (b) Globe

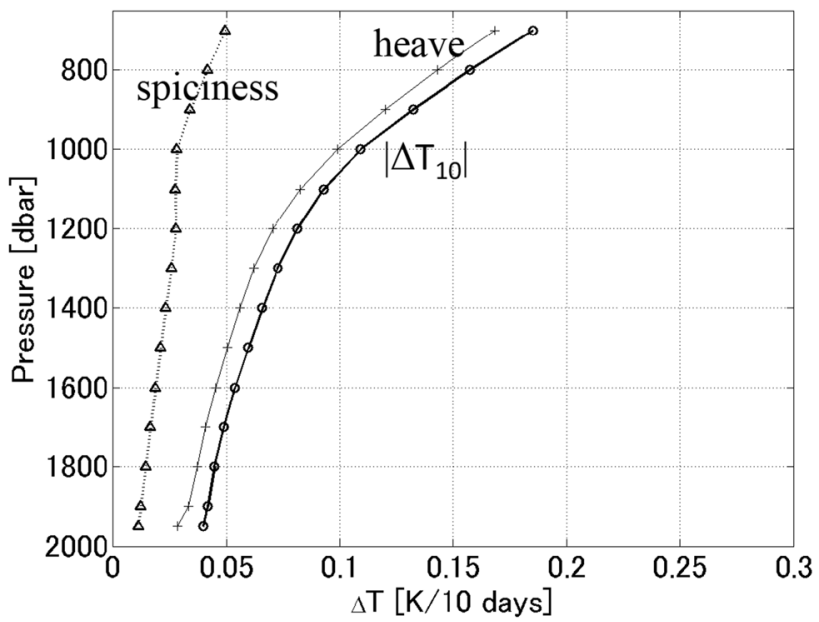

(d) $54-60 \circ \mathrm{S}, 120-150 \circ \mathrm{W}$

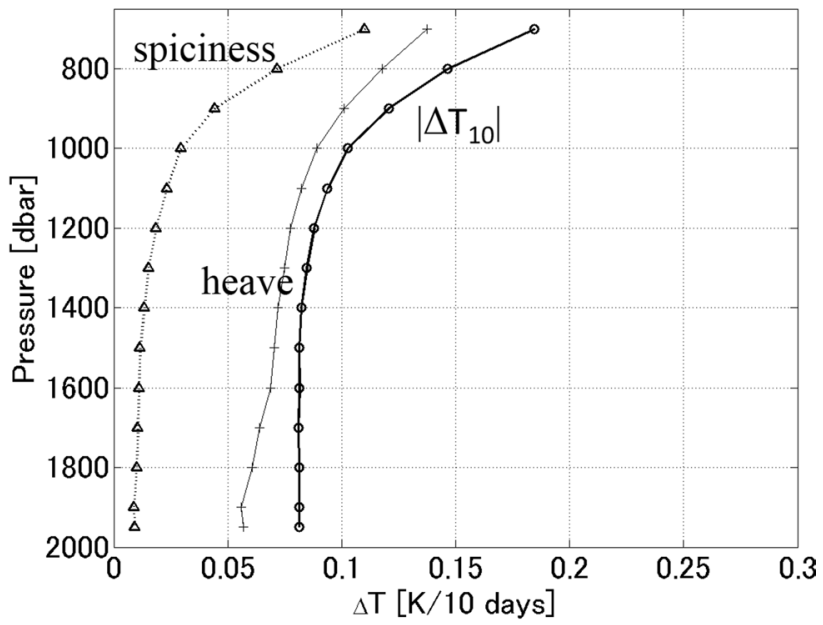

(f) $\quad 30-53 \circ \mathrm{S}, 30-60 \circ \mathrm{W}$

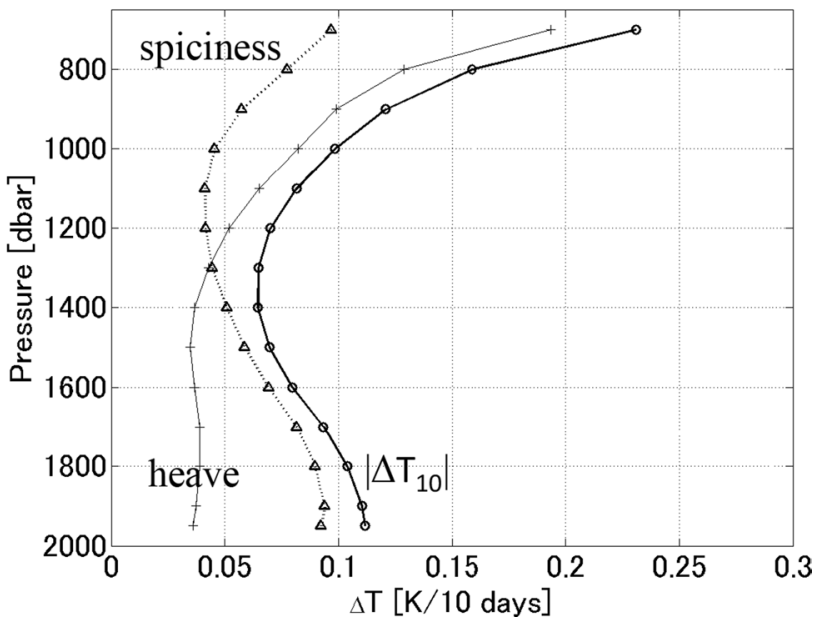

$40-60^{\circ} \mathrm{E}$ in the northwestern Indian Ocean, d $54-60^{\circ} \mathrm{S}, 120-150^{\circ} \mathrm{W}$ in the Southern Ocean, e $30-50^{\circ} \mathrm{N}, 2-30^{\circ} \mathrm{W}$ in the northeastern Atlantic Ocean, and f $30-53^{\circ} \mathrm{S}, 30-60^{\circ} \mathrm{W}$ in the southwestern Atlantic Ocean 
Fig. 9 Difference in $\left|\Delta T_{10}\right|$ between 1300 and 1950 dbar. Positive values mean that $\left|\Delta T_{10}\right|$ at $1950 \mathrm{dbar}$ is larger than at $1300 \mathrm{dbar}$. White contour denotes zero (color figure online)

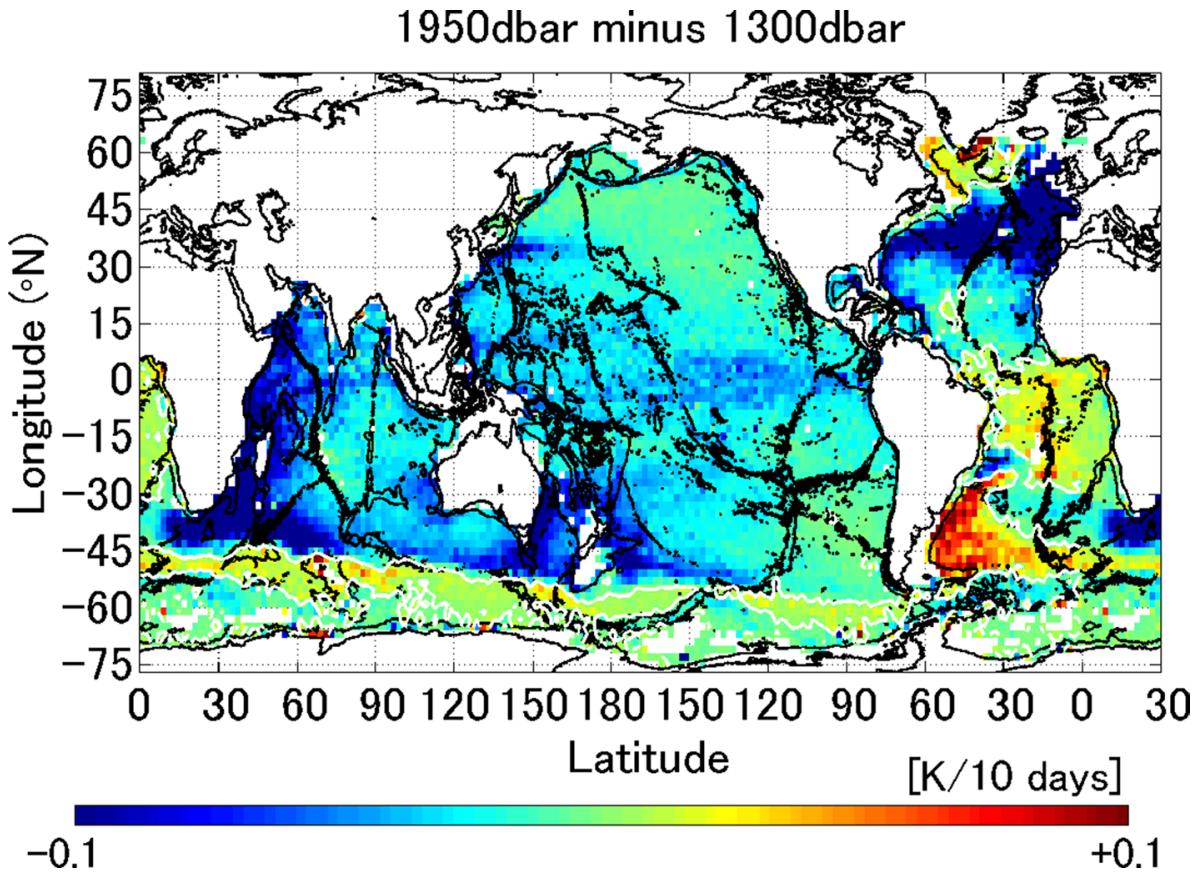

also enhanced along the Mariana, Hawaii, Kuril and Aleutian Islands, the Emperor Seamount Chain, and in Melanesia. It is large south of Mexico around $105^{\circ} \mathrm{W}$, where the East Pacific Rise is located, at 1950 dbar. On the other hand, $\left|\Delta T_{10}\right|$ is small north of about $30^{\circ} \mathrm{N}$, where the diurnal tidal frequency becomes subinertial and the diurnal baroclinic tide energy is prevented to propagate (Niwa and Hibiya 2011). Inoue et al. (2017) showed that vertical diffusivities in the 700-1000 dbar layer estimated from Argo data had meridional structures being smaller in the north, higher in the south in the region of $30-45^{\circ} \mathrm{N}, 165-175^{\circ} \mathrm{W}$. Their inferred diffusivities were enhanced around bottom topographies: the Izu-Ogasawara ridge, the Hawaiian Islands, and the Emperor Seamount Chain. Our results are consistent with their indications. $\left|\Delta S_{10}\right|$ is also large in the Kuroshio Extension and around the Kuril and Aleutian Islands, but quite small in the tropics and subtropics (Fig. 11c, d), because the vertical gradient of salinity is small in these regions. The mean $\left|\Delta S_{10}\right|$ is approximately 0.02 at $1000 \mathrm{dbar}$ and 0.01 at 1950 dbar at most, which are comparable to the accuracy of salinity measurement. Although the signal-tonoise ratio of $\left|\Delta S_{10}\right|$ is smaller than $\left|\Delta T_{10}\right|$, the characteristic of horizontal distribution will be reliable qualitatively. It has been known that strong tidal mixing occurs around the passes and straits of the Kuril and Aleutian Islands (Katsumata et al. 2004; Nakamura et al. 2010), which would also lead to enhancing the perturbations of temperature and salinity in these regions.

Figure 12 shows the standard deviation of $\left|\Delta T_{10}\right|$ normalized by the average, known as relative standard deviation or the coefficient of variation $(\mathrm{CV})$. If the mean $\left|\Delta T_{10}\right|$ is large and $\mathrm{CV}$ is low, around the equator and the Philippine Sea (Fig. 12a), for example, the perturbation of temperature is stably vigorous. On the other hand, high CV suggests that the amplitude of high frequency variations changes largely. For the North Pacific Ocean, CV is large in the areas east of Japan, around the Kuril, Aleutian Islands and the Emperor Seamount Chain, where $\left|\Delta T_{10}\right|$ varies with time, maybe due to passage of ocean eddies or atmospheric cyclones, as indicated by Kuwano-Yoshida et al. (2017). CV of more than 0.8 can be seen over wide regions in the North Atlantic Ocean and the Southern Hemisphere (Fig. 12b). The large CV in the North Atlantic Ocean and the Southern Ocean south of $35^{\circ} \mathrm{S}$ corresponds to the wind-induced near-inertial power input along storm tracks (Fig. 2b of Waterhouse et al. 2014). On the contrary, in the North Pacific Ocean east of $180^{\circ}$ and the Southern Hemisphere north of $35^{\circ} \mathrm{S}$, the $\mathrm{CV}$ distribution cannot be accounted for by the wind. Inoue et al. (2017) indicated that the vertical diffusivity did not have a simple linear relationship with the input of wind power. They inferred that the mixing may be related with the wind power, but the relationship may be complex.

For the North Pacific Ocean also, the heave component is the dominant contributor to $\Delta T_{10}$, and the effect of the spiciness component is basically much smaller, but it is relatively large in the Kuroshio and east of Japan at 1000 dbar (Fig. 13a). At 1950 dbar, the spiciness change is small in the Kuroshio and Kuroshio Extension, but notable in the western subtropics and along West Coast of the United States (Fig. 13b). The region with large spiciness change 
(a) $1950 \mathrm{dbar} /$ Potential temperature

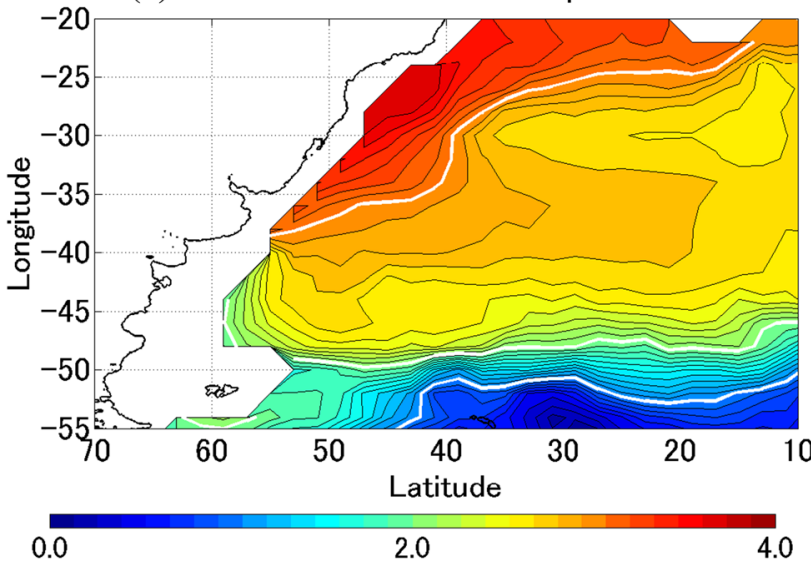

(b)

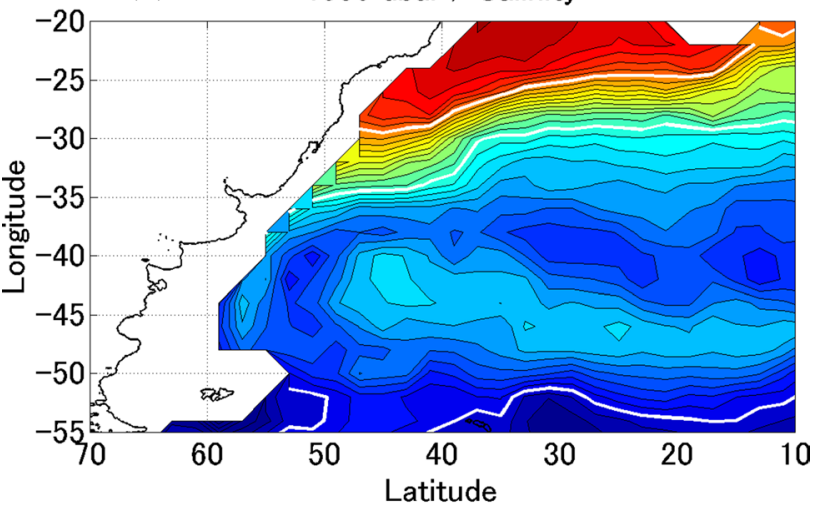

34.67

34.82

34.97

(c) $1950 \mathrm{dbar} /$ Neutral density

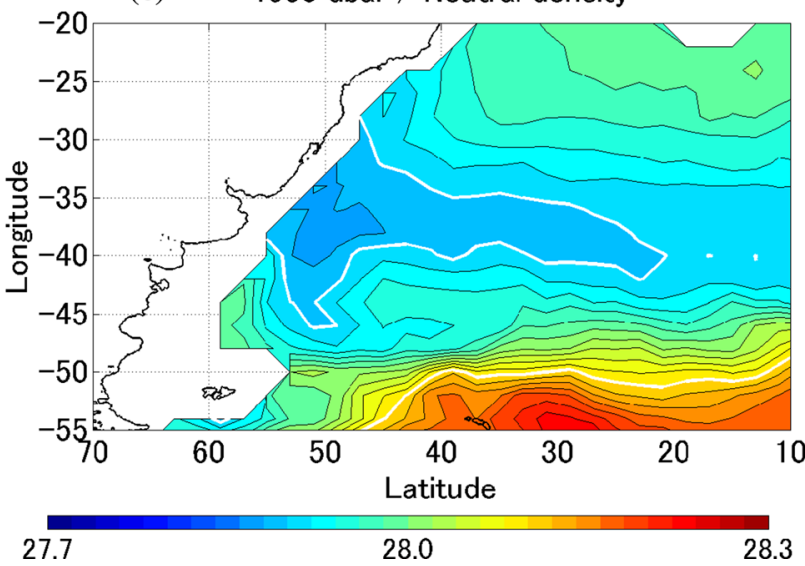

Fig. 10 Climatological means of a potential temperature, $\mathbf{b}$ salinity, and c neutral debsity at 1950 dbar in the southwestern Atlantic Ocean. White contours denote $1.0,2.0$, and $3.0^{\circ} \mathrm{C}$ in panel (a), 34.70, 34.80, and 34.90 in panel (b), and 27.9 and 28.1 in panel (c) (color figure online)

corresponds to where the horizontal gradient of spiciness is large (Fig. 13c). This suggests that the coincidence of the spiciness front and internal wave occurrence leads to generating spiciness anomaly through vigorous mixing of water masses.

There are a larger amount of Argo floats with a sampling interval of approximately 1 day in the North Pacific Ocean compared with the other Oceans (Fig. 14). Dot colors in Fig. 14 show temperature differences between successive observations with an interval of less than 1.5 days. These floats were intensively deployed in the central North Pacific, east off Japan, and the Philippine Sea. This spatial distribution of the samples is quite uneven, since the floats were deployed specially only in limited areas with specific purposes, but the concentration of large values in the Philippine Sea is noteworthy. Niwa and Hibiya (2011) demonstrated from a numerical simulation that the depth-integrated kinetic energy of diurnal internal tides was especially large in the Philippine Sea. Although 1-day sampling cannot resolve diurnal variations, Fig. 14 might reflect variability resulted from internal tides.

\section{Summary}

Previous numerical model studies suggest that the effects of atmospheric disturbance propagate to the intermediate and deep layers (Danioux et al. 2008; Kuwano-Yoshida et al. 2017), but short-term variations there have not been examined enough globally based on observations. To evaluate the variability on a time scale of 10 days at $2000 \mathrm{~m}$ depth, we analyzed 10-day changes of temperature and salinity using all available Argo floats throughout the Argo era. The 10-day variation, $\Delta T_{10}$ or $\Delta S_{10}$, is simply defined as the difference between two successive observations for each individual float at an isobaric surface. These values are averaged on $2^{\circ} \times 2^{\circ}$ grids or within some areas. The simplicity is the advantage of our procedures. Although it was not possible to do spectrum analysis or to resolve internal waves, our simple method successfully brought the spatial distribution of the small-scale spatiotemporal fluctuations in the intermediate layer into sharp relief.

At $1950 \mathrm{dbar}$, the mean $\left|\Delta T_{10}\right|$ and $\left|\Delta S_{10}\right|$ are noticeable and exceed the accuracy of the Argo measurement in the NEAO, the Argentine basin, and the NWIO. In the Southern Ocean, large $\left|\Delta T_{10}\right|$ is localized in some areas that are located over the ridges or leeward of the plateau. On the other hand, $\left|\Delta T_{10}\right|$ at 1000 dbar is more remarkable along the WBCs. We examined the effect of horizontal shift of the floats, and confirmed that its contribution to $\Delta T_{10}$ is relatively small and $\Delta T_{10}$ is mainly accounted for by temporal change, although the effect of the horizontal shift might be larger than our estimation in the vicinity of $T / S$ fronts. Basically, $\Delta T_{10}$ at isobaric surfaces is accounted for by the heave component, but the spiciness component is dominant or comparable to 
(a) $1000 \mathrm{dbar} /$ Tdif mean

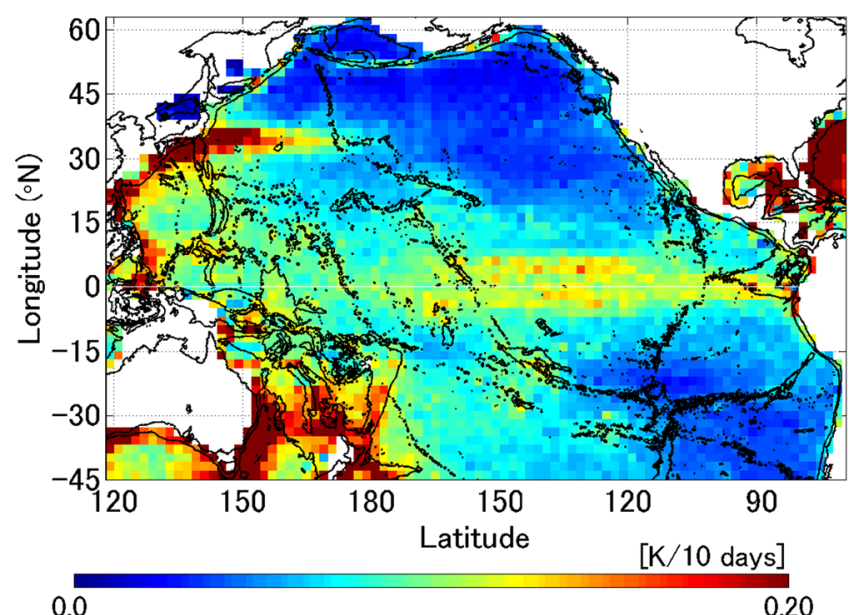

(c) $1000 \mathrm{dbar} /$ Sdif mean

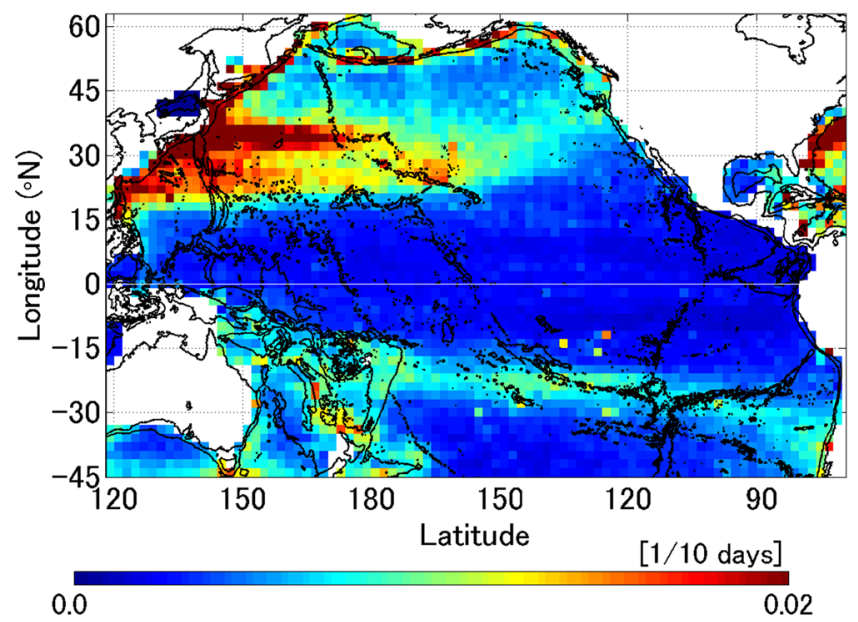

(b) $1950 \mathrm{dbar} /$ Tdif mean

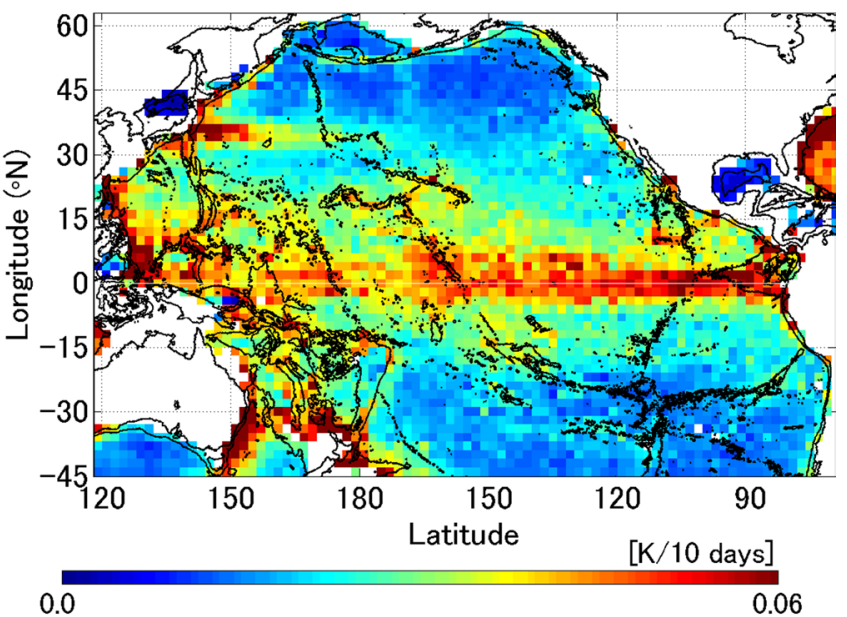

(d) $1950 \mathrm{dbar} /$ Sdif mean

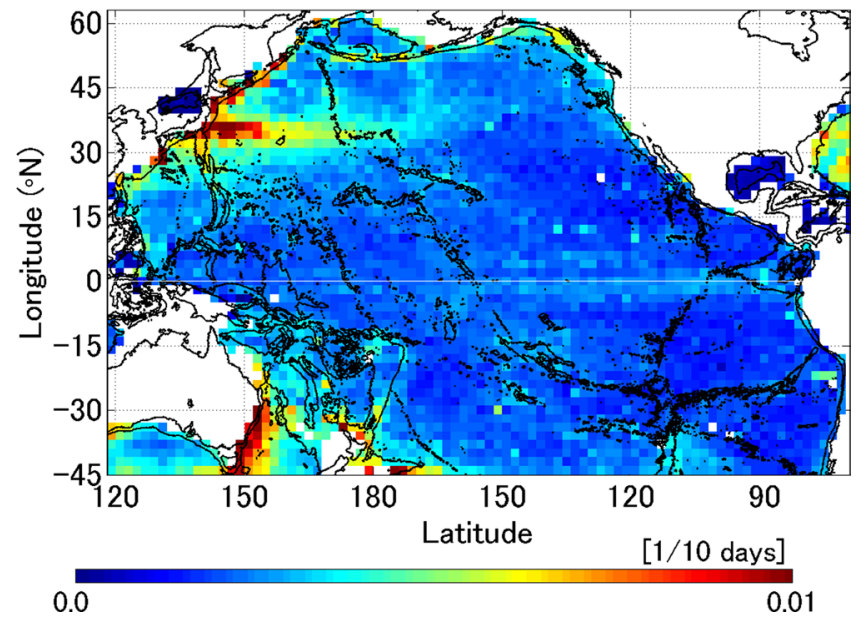

Fig. 11 Mean of $\mathbf{a}, \mathbf{b}\left|\Delta T_{10}\right|$ and $\mathbf{c}, \mathbf{d}\left|\Delta S_{10}\right|$ for the Pacific Ocean. Left panels a, $\mathbf{c}$ for $1000 \mathrm{dbar}$, and right panels $\mathbf{b}, \mathbf{d}$ for $1950 \mathrm{dbar}$. Note that the data shown here are the same as Fig. $2 \mathrm{a}-\mathrm{d}$, but the color scales are different (color figure online)

the heave component in the NEAO and the Argentine basin. Large $\Delta T_{10}$ basically corresponds to bottom topography and strong currents, and is qualitatively consistent with the indications of Hennon et al. (2014) who used special hourly Argo data at the parking depth, and with theoretical studies (Nikurashin and Ferrari 2011; Niwa and Hibiya 2011). The differences in the 10-day changes between the Oceans would reflect the differences in stabilities in the intermediate layer (Fig. 4).

Below 700 dbar, $\Delta T_{10}$ decreases with depth monotonically and is dominated by the heave component most of the world. This suggests that wind energy input from the sea surface is dominant and attenuated with depth. In some areas with large $\Delta T_{10}$ in the Southern Ocean, however, mean $\mathrm{I} \Delta T_{10} \mathrm{l}$ is vertically homogeneous below $1200 \mathrm{dbar}$. This might be due to the effect of turbulence induced by the bottom topography. In the NEAO, both the heave and spiciness components are comparable to each other, and the maximum of $\left|\Delta T_{10}\right|$ is located at $1300 \mathrm{dbar} .\left|\Delta T_{10}\right|$ increases with depth and the spiciness component becomes larger below 1300 dbar in the Argentine basin. The features of mixing in these regions in the Atlantic Ocean seem to be unique and different from the rest of the world, and further intensive studies are needed. 
Fig. 12 Standard deviation of

$\left|\Delta T_{10}\right|$ normalized by mean

$\left|\Delta T_{10}\right|$ (coefficient of variation,

CV) at $1950 \mathrm{dbar}$. a North

Pacific Ocean, and $\mathbf{b}$ globe. A median filter of $5 \times 5$ is applied
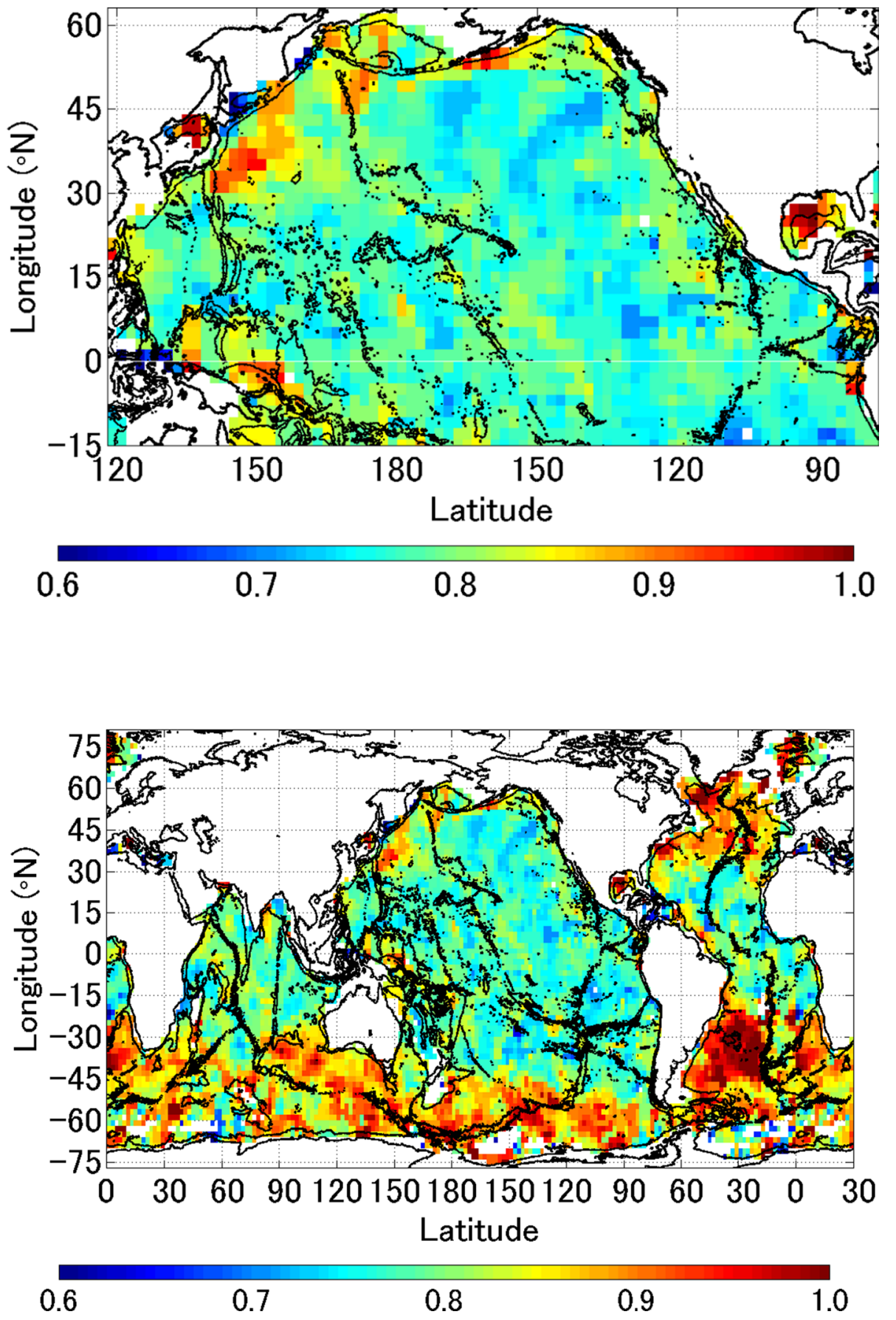
(a) $1000 \mathrm{dbar} /$ Tdif mean

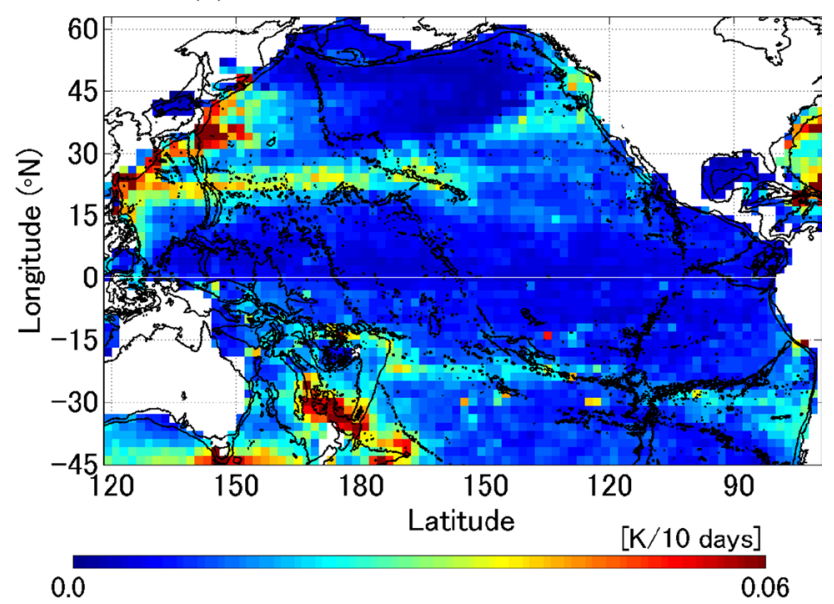

(b) $1950 \mathrm{dbar} /$ Tdif mean

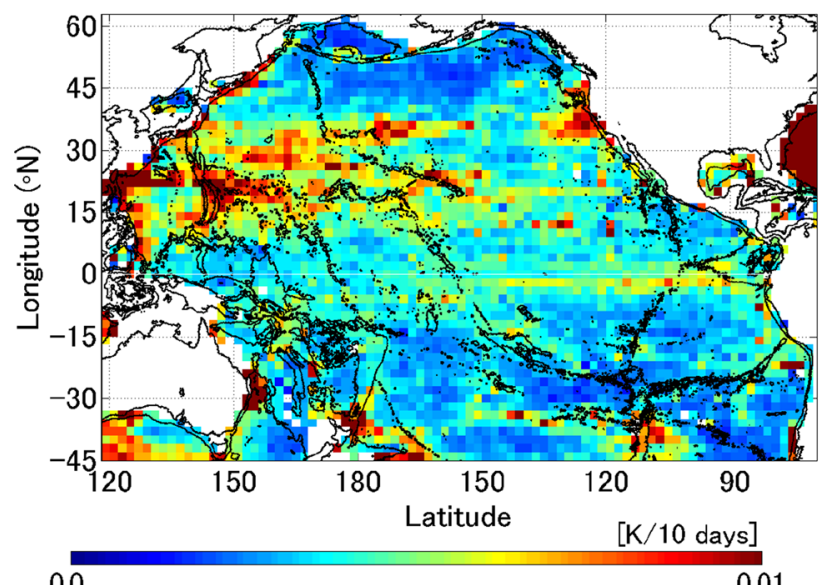

0.0

(c) $1950 \mathrm{dbar} /$ spiciness

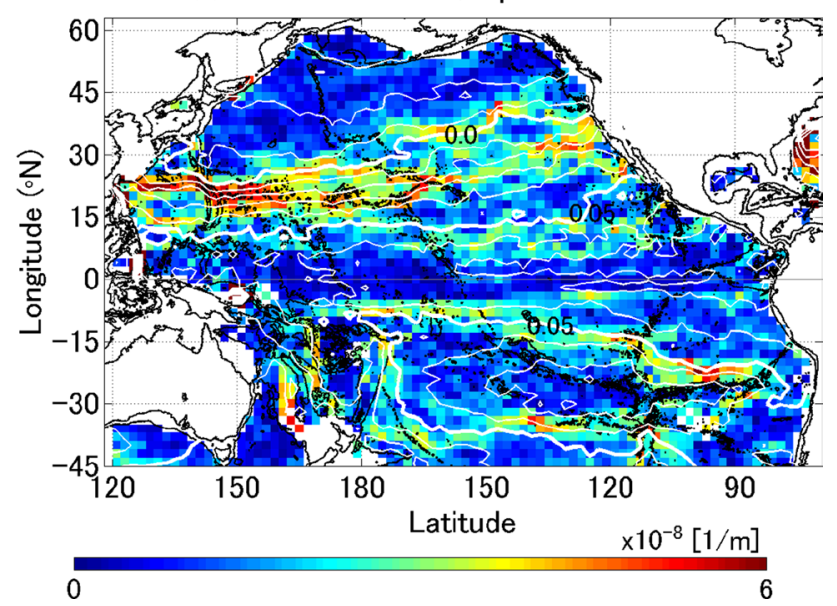

Fig. 13 Mean of the spiciness component at a 1000 dbar and b 1950 dbar. c Spiciness referenced to a pressure of $2000 \mathrm{dbar}\left(\mathrm{kg} \mathrm{m}^{-3}\right.$, contour) and its horizontal gradient (color) at 1950 dbar. Intervals of thin and bold contours are 0.01 and 0.05 , respectively. Note that the color scales are different from those in Fig. 11 (color figure online)
$\Delta T_{10}$ and $\Delta S_{10}$ in the Pacific Ocean are smaller compared with the other oceans, probably because the intermediate circulation is relatively weak. Detailed investigation of the variability at 2000 dbar is, however, necessary even for the Pacific Ocean to advance research of turbulence and design the observation system by the deep Argo float. Within the Pacific Ocean, $\left|\Delta T_{10}\right|$ is large around the eastern tropics, the WBCs, the Mariana, Hawaii, Kuril and Aleutian Islands, the Emperor Seamount Chain, and in Melanesia. This spatial distribution appears to reflect the bottom topography and internal wave, although CV also suggests the effect of cyclones. The spiciness component is relatively large around the Kuril Islands, in the western subtropics and along West Coast of the United States at 1950 dbar, where the horizontal gradient of spiciness is large and vigorous mixing of water masses is expected.

The comparison with the standard deviation of the gridded monthly data suggests that our $\left|\Delta T_{10}\right|$ successfully captures small-scale spatiotemporal variations that does not clearly appear in the monthly data. Our analysis identified the areas where the variability is large at $2000 \mathrm{~m}$ depth based on the abundant in situ observations. The results in this study contribute to designing the deep Argo observation plan, and are also useful as a benchmark when the performance of a numerical model is evaluated. The authors dealt with only $T / S$ differences, and as a next step, advanced measurements and analyses are needed to clarify what really causes the 10-day variation and how the enhanced $\Delta T_{10}$ is associated with large-scale circulations. 
Fig. 14 Position of the Argo floats with an observation interval of less than 1.5 days (gray dots). The temperature differences between successive observations at 1950 dbar are classified by color. Blue and red dots denote more than $0.05 \mathrm{~K} /$ day and more than $0.1 \mathrm{~K} /$ day, respectively (color figure online)

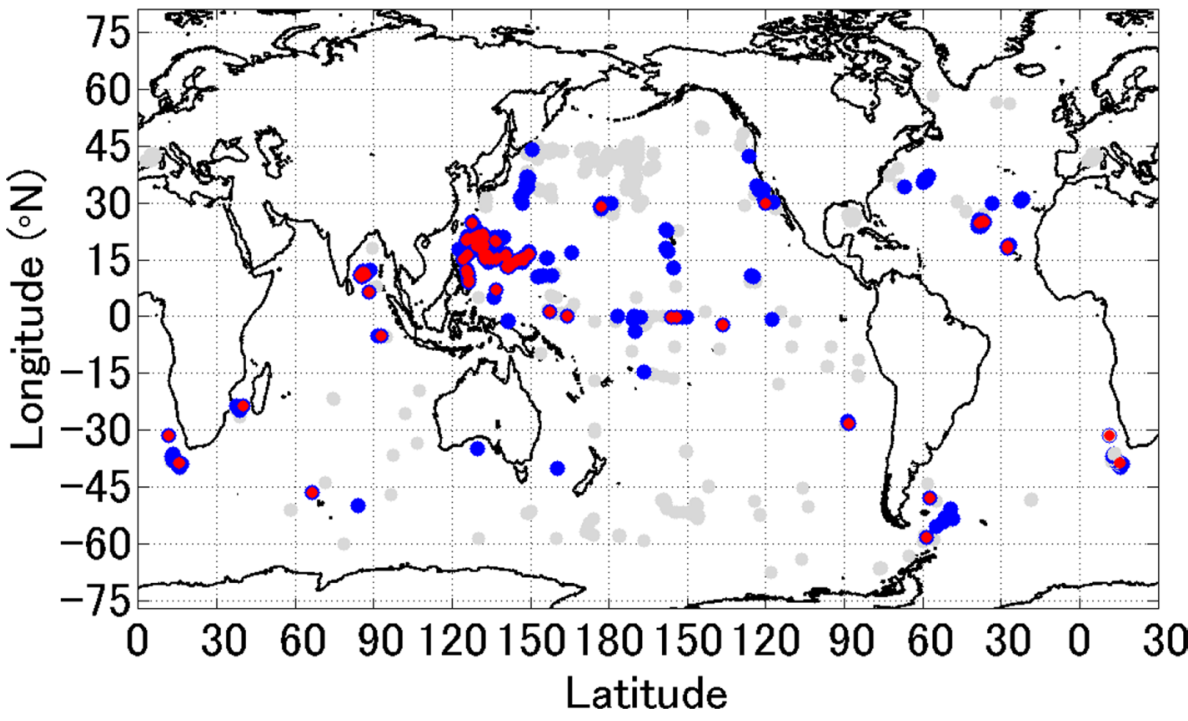

\begin{abstract}
Acknowledgements This work was supported by the Ministry of Education, Culture, Sports, Science and Technology (MEXT) of Japan, Grant-in-Aid for Scientific Research on Innovative Areas (19H05700), and the Japan Society for the Promotion of Science (JSPS) Grants-inAid for Scientific Research (A) (KAKENHI) (18H03726). We downloaded the Gibbs-SeaWater Oceanographic Toolbox from the site of the Thermodynamic Equation of Seawater-2010 (TEOS-10) (http://www. teos-10.org/software.htm). The Argo data were collected and made freely available by the International Argo Program and the national programs that contribute to it (https://argo.ucsd.edu, https://www.oceanops.org). The Argo Program is part of the Global Ocean Observing System. Members of the Argo data management team in the Research Institute for Global Change of the Japan Agency for Marine-Earth Science and Technology (JAMSTEC) helped with the use of Argo float data and the refinement of the data set MOAA GPV (http://www.jamst ec.go.jp/ARGO/argo_web/argo/?page_id=80\&lang=en).
\end{abstract}

Open Access This article is licensed under a Creative Commons Attribution 4.0 International License, which permits use, sharing, adaptation, distribution and reproduction in any medium or format, as long as you give appropriate credit to the original author(s) and the source, provide a link to the Creative Commons licence, and indicate if changes were made. The images or other third party material in this article are included in the article's Creative Commons licence, unless indicated otherwise in a credit line to the material. If material is not included in the article's Creative Commons licence and your intended use is not permitted by statutory regulation or exceeds the permitted use, you will need to obtain permission directly from the copyright holder. To view a copy of this licence, visit http://creativecommons.org/licenses/by/4.0/.

\section{References}

Akima H (1970) A new method for interpolation and smooth curve fitting based on local procedures. J Assoc Comput Mech 17:589-603

Argo (2021) Argo float data and metadata from Global Data Assembly Centre (Argo GDAC). SEANOE.https://doi.org/10.17882/42182

Beal LM, Ffield A, Gordon AK (2000) Spreading of Red Sea overflow waters in the Indian Ocean. J Geophys Res 105:8549-8564. https://doi.org/10.1029/1999JC900306
Bozec A, Lozier MS, Chassignet EP, Halliwell GR (2011) On the variability of the Mediterranean Outflow Water in the North Atlantic from 1948 to 2006. J Geophys Res 116:C09033. https://doi.org/ 10.1029/2011JC007191

Bryden HL, Roemmich DH, Church JA (1991) Ocean heat transport across $24^{\circ} \mathrm{N}$ in the Pacific. Deep-Sea Res 38:297-324

Danioux E, Klein P, Rivière P (2008) Propagation of wind energy into the deep ocean through a fully turbulent mesoscale eddy field. J Phys Oceanogr 38:2224-2241. https://doi.org/10.1175/2008J PO3821.1

Desbruyères D, McDonagh EL, King BA (2017) Global and full-depth ocean temperature trends during the early twenty-first century from Argo and repeat hydrography. J Clim 30:1985-1997. https:// doi.org/10.1175/JCLI-D-16-0396.1

Ferrari R, Polzin KL (2005) Finescale structure of the T-S relation in the Eastern North Atlantic. J Phys Oceanogr 35:1437-1454. https://doi.org/10.1175/JPO2763.1

Fukasawa M, Freeland H, Perkin R, Watanabe T, Uchida H, Nishina A (2004) Bottom water warming in the North Pacific Ocean. Nature 427:825-827. https://doi.org/10.1038/nature02337

Hennon TD, Riser SC, Alford MH (2014) Observations of internal gravity waves by Argo floats. J Phys Oceanogr 44:2370-2386. https://doi.org/10.1175/JPO-D-13-0222.1

Hosoda S, Minato S, Shikama N (2006) Seasonal temperature variation below the thermocline detected by Argo floats. Geophys Res Lett 33:L13604. https://doi.org/10.1029/2006GL026070

Hosoda S, Ohira T, Nakamura T (2008) A monthly mean dataset of global oceanic temperature and salinity derived from Argo float observations. JAMSTEC Rep Res Dev 8:47-59. https://doi.org/ 10.5918/jamstecr.8.47

Hu RJ, Wei M (2013) Intraseasonal oscillation in global ocean temperature inferred from Argo. Adv Atmos Sci 30:29-40. https:// doi.org/10.1007/s00376-012-2045-4

Inoue R, Watanabe M, Osafune S (2017) Wind-induced mixing in the North Pacific. J Phys Oceanogr 47:1587-1603. https://doi.org/10. 1175/JPO-D-16-0218.1

Katsumata K, Ohshima KI, Kono T, Itoh M, Yasuda I, Volkov YN, Wakatsuchi M (2004) Water exchange and tidal currents through the Bussol' Strait revealed by direct current measurements. J Geophys Res 109:C09S06. https://doi.org/10.1029/2003JC001864 
Kobayashi T (2018) Rapid volume reduction in antarctic bottom water off the Adélie/George V land coast observed by deep floats. Deep Sea Res I 140:95-117. https://doi.org/10.1016/j.dsr.2018.07.014

Kouketsu S, Doi T, Kawano T, Masuda S, Sugiura N, Sasaki Y, Toyoda T, Igarashi H, Kawai Y, Katsumata K, Uchida H, Fukasawa M, Awaji T (2011) Deep ocean heat content changes estimated from observation and reanalysis product and their influence on sea level change. J Geophys Res 116:C03012. https://doi.org/10. 1029/2010JC006464

Kuwano-Yoshida A, Sasaki H, Sasai Y (2017) Impact of explosive cyclones on the deep ocean in the North Pacific using an eddyresolving ocean general circulation model. Geophys Res Lett 44:320-329. https://doi.org/10.1002/2016GL071367

Mathews AJ, Singhruck P, Heywood KJ (2007) Deep ocean impact of a Madden-Julian oscillation observed by Argo floats. Science 318:1765-1769. https://doi.org/10.1126/science.1147312

McDougall TJ, Barker PM (2011) Getting started with TEOS-10 and the Gibbs Seawater (GSW) Oceanographic Toolbox, 28 pp. SCOR/IAPSO WG127. ISBN 978-0-646-55621-5

Nakamura T, Isoda Y, Mitsudera H, Takagi S, Nagasawa M (2010) Breaking of unsteady lee waves generated by diurnal tides. Geophys Res Lett 37:L04602. https://doi.org/10.1029/2009GL041456

Nikurashin M, Ferrari R (2011) Global energy conversion rate from geostrophic flows into internal lee waves in the deep ocean. Geophys Res Lett 38:L08610. https://doi.org/10.1029/2011GL046576
Niwa Y, Hibiya T (2011) Estimation of baroclinic tide energy available for deep ocean mixing based on three-dimensional global numerical simulations. J Oceanogr 67:493-502. https://doi.org/10.1007/ s10872-011-0052-1

Roach CJ, Balwada D, Speer K (2018) Global observations of horizontal mixing from Argo float and surface drifter trajectories. J Geophys Res Oceans 123:4560-4575. https://doi.org/10.1029/ 2018JC013750

Roemmich D, Gilson J, Cornuelle B, Weller R (2001) Mean and time-varying meridional transport of heat at the tropical/subtropical boundary of the North Pacific Ocean. J Geophys Res 106:8957-8970

Toyama K, Iwasaki A, Suga T (2015) Interannual variation of annual subduction rate in the North Pacific estimated from a gridded Argo product. J Phys Oceanogr 45:2276-2293. https://doi.org/ 10.1175/JPO-D-14-0223.1

Valla D, Piola AR, Meinen CS, Campos E (2018) Strong mixing and recirculation in the northwestern Argentine Basin. J Geophys Res Oceans 123:4624-4648. https://doi.org/10.1029/2018JC013907

Waterhouse AF et al (2014) Global patterns of diapycnal mixing from measurements of the turbulent dissipation rate. J Phys Oceanogr 44:1854-1872. https://doi.org/10.1175/JPO-D-13-0104.1

Wong APS et al (2020) Argo data 1999-2019: Two million temperature-salinity profiles and subsurface velocity observations from a global array of profiling floats. Front Mar Sci. https://doi.org/10. 3389/fmars.2020.00700 